Research, Society and Development, v. 10, n. 3, e8210311292, 2021

(CC BY 4.0) | ISSN 2525-3409 | DOI: http://dx.doi.org/10.33448/rsd-v10i3.11292

\title{
Inoculante líquido contendo estirpe de Azospirillum brasilense, via sementes na cultura do milho, associado à adubação nitrogenada promovendo ganhos em produtividade
}

\author{
Liquid inoculant containing of Azospirillum brasilense strain, via seeds in the corn crops, associated \\ with nitrogen fertilization promoting productivity gains \\ Inoculante líquido que contiene la cepa Azospirillum brasilense, mediante de semillas em el cultivo \\ de maíz, asociado a la fertilización nitrógenada que promueve ganancias de produtividad
}

Recebido: 05/01/2020 | Revisado: 08/01/2020 | Aceito: 05/05/2020 | Publicado: 03/03/2021

Vandeir Francisco Guimarães

ORCID: https://orcid.org/0000-0001-7117-1905

Universidade Estadual do Oeste do Paraná, Brasil E-mail: vandeirfg@yahoo.com.br

Jeferson Klein

ORCID: https://orcid.org/0000-0002-2075-362X Biogenesis Centro de Pesquisa e Desenvolvimento Ltda, Brasil E-mail: jefersonklein@yahoo.com.br

Débora Kestring Klein

ORCID: https://orcid.org/0000-0002-5443-642X

Biogenesis Centro de Pesquisa e Desenvolvimento Ltda, Brasil E-mail: deborakestring@yahoo.com.br

\begin{abstract}
Resumo
Objetivou avaliar a eficiência agronômica a campo de inoculante líquido contendo estirpes Ab-V5 e Ab-V6 de Azospirillum brasiliense, para a cultura do milho, via tratamento de sementes, associado à adubação nitrogenada. Foram conduzidos quatro ensaios em delineamento de blocos casualizados com sete tratamentos e quatro repetições.

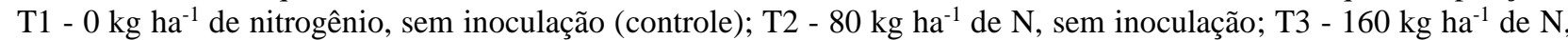
(SI); T4 - $80 \mathrm{~kg} \mathrm{ha}^{-1} \mathrm{de} \mathrm{N}$ + Inoculação de padrão registrado, contendo A. brasilense (Ab-V5 e Ab-V6), $100 \mathrm{~mL} 25 \mathrm{~kg}$ ${ }^{1}$ de sementes; T5 - $80 \mathrm{~kg} \mathrm{ha}^{-1} \mathrm{de} \mathrm{N}$ + FERTIBIO Azospirillum 'Líquido' na $100 \mathrm{~mL} 25 \mathrm{~kg}^{-1}$ de sementes; T6 - $80 \mathrm{~kg}$ ha $^{-1}$ de N + FERTIBIO Azospirillum 'Líquido' $150 \mathrm{~mL} 25 \mathrm{~kg}^{-1}$ de sementes; e T7 - $80 \mathrm{~kg} \mathrm{ha}^{-1} \mathrm{de} \mathrm{N}+$ FERTIBIO Azospirillum 'Líquido' $200 \mathrm{~mL} 25 \mathrm{~kg}^{-1}$ de sementes. O inoculante apresentou eficiência agronômica semelhante ao inoculante padrão registrado, quando foi utilizado, via inoculação de sementes com suplementação de $80 \mathrm{~kg} \mathrm{ha}^{-1}$ de nitrogênio e foi superior estatisticamente ao controle e ao tratamento inoculado com metade da dose de $\mathrm{N}$. De acordo com os resultados, fica comprovada a eficiência do inoculante líquido (estirpes Ab-V5 e Ab-V6) de A. brasiliense, sendo recomendada a dose de $100 \mathrm{~mL} 25 \mathrm{~kg}^{-1}$ de sementes, via tratamento de sementes, para a cultura do milho, utilizando-se a metade da dose de fertilizante nitrogenado.
\end{abstract}

Palavras-chave: Zea mays L.; Bactérias promotoras de crescimento de plantas; Fertilização nitrogenada; Inoculação de sementes; Produtividade.

\begin{abstract}
The objective was to evaluate the efficiency in the field of the liquid inoculant with the strains Ab-V5 and Ab-V6 of Azospirillum brasilense, for corn, through seed treatment, associated with nitrogen fertilization. They were conducted in a randomized block design with seven treatments and four replications. T1 - $0 \mathrm{~kg} \mathrm{ha}^{-1}$ of nitrogen, without inoculation (control); T2 - $80 \mathrm{~kg} \mathrm{ha}^{-1}$ of $\mathrm{N}$, without inoculation; T3 - $160 \mathrm{~kg} \mathrm{ha}^{-1}$ of $\mathrm{N}$; T4 $-80 \mathrm{~kg} \mathrm{ha}^{-1}$ of N + Inoculation registered standard liquid, containing A. brasilense (Ab-V5 and $\mathrm{Ab}-\mathrm{V} 6$ ), $100 \mathrm{~mL} 25 \mathrm{~kg}^{-1}$ of seeds; $\mathrm{T} 5-80$ $\mathrm{kg} \mathrm{ha}^{-1}$ of N + FERTIBIO Azospirillum 'Liquid' in $100 \mathrm{~mL} 25 \mathrm{~kg}^{-1}$ of seeds; T6 - $80 \mathrm{~kg} \mathrm{ha}^{-1}$ of N + FERTIBIO Azospirillum 'Liquid' $150 \mathrm{~mL} 25 \mathrm{~kg}^{-1}$ of seeds; and T7 - $80 \mathrm{~kg} \mathrm{ha}^{-1}$ of $\mathrm{N}+$ FERTIBIO Azospirillum 'Liquid' $200 \mathrm{~mL}$ $25 \mathrm{~kg}^{-1}$ of seeds. The liquid inoculant showed efficiency similar to the registered standard inoculant, when it was used, via seed inoculation with supplementation of $80 \mathrm{~kg} \mathrm{ha}^{-1}$ of nitrogen. This one stood out, being statistically superior to the control and to the treatment where half the dose of nitrogen recommended was provided, without inoculation. According to the results, the efficiency of the liquid inoculant (strains Ab-V5 and Ab-V6) of A. brasilense, being recommended the dose of $100 \mathrm{~mL} 25 \mathrm{~kg}^{-1}$ of inoculant seeds, via seed treatment, for the corn crop, using half the dose of nitrogen fertilizer for the crop.
\end{abstract}

Keywords: Zea mays L.; Plant growth promoting bacteria; Nitrogen fertilization; Seed inoculation; Productivity. 


\section{Resumen}

El objetivo fue evaluar la eficiencia en campo del inoculante líquido FERTIBIO Azospirillum, con cepas Ab-V5 y Ab-V6 de Azospirillum brasiliense, para maíz, mediante tratamiento de semillas, asociado a fertilización nitrogenada. Se realizaron en un diseño de bloques al azar con siete tratamientos y cuatro repeticiones. T1 - $0 \mathrm{~kg} \mathrm{ha}^{-1}$ de nitrógeno, sin inoculación (testigo); T2 - $80 \mathrm{~kg} \mathrm{ha}^{-1} \mathrm{de} \mathrm{N}$, sin inoculación; T3 - $160 \mathrm{~kg} \mathrm{ha}^{-1} \mathrm{de} \mathrm{N}$; T4 - $80 \mathrm{~kg} \mathrm{ha-1}$ de N + Inoculación líquido estándar registrado, conteniendo A. brasilense (Ab-V5 y Ab-V6), 100 mL $25 \mathrm{~kg}^{-1}$ de semillas; T5 - $80 \mathrm{~kg} \mathrm{ha}^{-1}$ de $\mathrm{N}+$ FERTIBIO Azospirillum 'Liquid' en $100 \mathrm{~mL} 25 \mathrm{~kg}^{-1}$ de semillas; T6 - $80 \mathrm{~kg} \mathrm{ha}{ }^{-1} \mathrm{de} \mathrm{N}+$ FERTIBIO Azospirillum 'Liquid' $150 \mathrm{~mL} 25 \mathrm{~kg}^{-1}$ de semillas; y $\mathrm{T} 7-80 \mathrm{~kg} \mathrm{ha}^{-1} \mathrm{de} \mathrm{N}+$ FERTIBIO Azospirillum 'Liquid' $200 \mathrm{~mL} 25 \mathrm{~kg}^{-1}$ de semillas. El inoculante mostró eficiencia similar al inoculante estándar registrado, cuando se utilizó, mediante inoculación de semillas con suplementación de $80 \mathrm{~kg} \mathrm{ha}^{-1}$ de nitrógeno. Este fue estadísticamente superior al testigo y al tratamiento donde se aportó la mitad de la dosis de nitrógeno, sin inoculación con $A$. brasilense. Según los resultados, la eficiencia del inoculante líquido (cepas Ab-V5 y Ab-V6) de A. brasilense, recomendándose la dosis de $100 \mathrm{~mL} 25 \mathrm{~kg}^{-1}$ de semillas inoculantes, vía tratamiento de semillas, para el cultivo de maíz, utilizando la mitad de la dosis de fertilizante nitrogenado para el cultivo.

Palabras clave: Zea mays L.; Bacterias promotoras del crescimiento vegetal; Fertilización con nitrógeno; Inoculación de semillas; Productividad.

\section{Introdução}

O milho (Zea mays L.) é o cereal mais cultivado no Brasil e no mundo. Apresenta grande relevância no contexto econômico e produtivo no Brasil. Com isso, para fortalecer ainda mais a cultura no país, novas técnicas surgem com a finalidade de contribuir com aumento de produtividade de forma sustentável.

Os sistemas produtivos no Brasil e no mundo, têm sido baseados em monocultivo ou sucessões de culturas de grande interesse econômico. No Brasil pode-se destacar a sucessão soja e milho de segunda safra. Estes sistemas são frágeis, quando se considera a sustentabilidade do setor produtivo, mas atendem as demandas econômicas de curto prazo. Sendo assim, técnicas que visem minimizar o impacto deste sistema, principalmente quanto ao uso excessivo de fertilizantes, são bem aceitas e são alvo de pesquisas nas últimas décadas.

Uma alternativa é maximizar a eficiência de uso dos fatores de produção, como água, luz, nutrientes, etc. Neste contexto, bactérias promotoras de crescimento vegetal (BPCV), tem sido uma alternativa. A utilização das BPCV no Brasil tem enfoque nas pesquisas desde a década de 50, quando a Dra. Johanna Döbereiner isolou de solos ácidos da "Baixada Fluminense" amostras da Azotobacter. Esses estudos ganharam evidência com a descoberta de bactérias fixadoras de nitrogênio associadas à rizosfera de gramíneas, que abriu um leque de diferentes linhas de pesquisa na área (Döbereiner; Ruschel, 1958; Döbereiner, 1966). Desde então muito foi descoberto quanto a características adicionais desses microrganismos, demonstrando que a fixação biológica de nitrogênio é apenas uma das muitas aplicações agrícolas resultantes da pesquisa com BPCV (Baldani \& Baldani, 2005).

De comportamento endofítico e epifítico, as BPCV têm a capacidade de colonizar diversas partes da planta, promovendo vários efeitos benéficos como a fixação biológica de nitrogênio, produção de fitohormônios (auxinas, citocininas e giberelinas), controle biológico, solubilização de fosfatos minerais, redução da produção de etileno nos tecidos, entre outros. Estes efeitos culminam com maior desenvolvimento das plantas e capacidade de absorção de água e nutrientes, retardamento da senescência dos tecidos e menor susceptibilidade ao ataque de pragas e doenças, o que em muitos casos, resulta em manutenção da produtividade, mesmo com a redução de fornecimento de insumos, como os fertilizantes nitrogenados, pelo aumento da eficiência de uso no sistema produtivo. São vários os relatos na literatura sobre a eficiência agronômica da utilização destas bactérias em inoculantes em culturas de grande interesse econômico, como milho, trigo e arroz (Döbereiner, 1997).

Dentre as espécies de bactérias que são estudadas quanto à promoção de crescimento em plantas está o Azospirillum brasilense. Essa é caracterizada como endofítica facultativa, que pode colonizar tanto a rizosfera como o interior das plantas 
(Baldani e Baldani, 2005). Esta associação tem sido relatada como positiva para várias culturas. Neste sentido, é crescente a demanda por inoculantes à base de A. brasilense, visto a comprovada eficiência agronômica desta espécie, sendo utilizados em gramíneas de interesse econômico e mais recentemente em coinoculação com bactérias simbiônticas na cultura da soja.

Diante das justificativas apresentadas e contextualização quanto ao estado da arte da pesquisa com BPCV, objetivouse com o presente estudo avaliar a eficiência agronômica a campo do inoculante líquido da empresa FERTIBIO do Brasil, contendo a bactéria Azospirillum brasiliense estirpes Ab-V5 e Ab-V6, no tratamento de sementes da cultura do milho, associado à adubação nitrogenada.

\section{Metodologia}

\section{Local experimental}

O estudo foi conduzido em quatro localidades: Toledo/PR Coordenadas: Latitude de 2440'12" S e Longitude 53³9'19” O. Classificação do solo: LATOSSOLO VERMELHO distroférrico típico de textura muito argilosa; Palotina/PR. Coordenadas: Latitude de $24^{\circ} 17^{\prime} 44^{\prime \prime} \mathrm{S}$ e Longitude 5349'40” O. Classificação do solo: LATOSSOLO VERMELHO eutroférrico de textura muito argilosa; São Miguel do Iguaçu/PR. Latitude de 25²3'07’S e Longitude 54²'33” O. Classificação do solo: NITOSSOLO VERMELHO eutroférrico de textura muito argilosa. Cascavel - PR. Latitude de

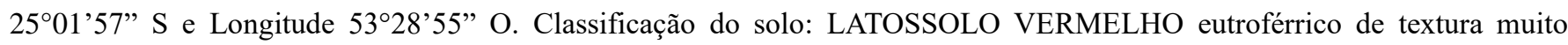
argilosa. Os ensaios foram realizados de outubro de 2017 a fevereiro de 2018. A seguir, estão as coordenadas geográficas, altitude e tipo de solo, das áreas (Embrapa, 2013).

\section{Determinação do solo e condições climáticas durante a condução do experimento}

As caracterizações químicas e físicas dos solos das áreas experimentais foram realizadas através da análise de material, proveniente de amostras compostas por dez subamostras em cada área experimental, na profundidade de 0 a 0,20 m. Os resultados são apresentados nas Tabelas 1, 2, 3 e 4.

Tabela 1. Características químicas e granulométricas do solo coletado na camada de 0,0-0,2m proveniente da Estação Experimental Biogenesis, Centro de Pesquisa e Desenvolvimento, localizada no município de Toledo - PR, $2017 / 2018$.

\begin{tabular}{|c|c|c|c|c|c|c|c|c|c|c|}
\hline \multicolumn{11}{|c|}{ Características químicas (a) } \\
\hline $\mathrm{pH}$ & $\mathrm{V}$ & $\mathrm{P}$ & $\mathrm{MO}$ & $\mathrm{Ca}^{2+}$ & $\mathrm{Mg}^{2+}$ & $\mathrm{K}^{+}$ & $\mathrm{Al}^{3+}$ & $\mathrm{H}+\mathrm{Al}$ & SB & CTC \\
\hline $\mathrm{CaCl}_{2}$ & $-\%-$ & $\mathrm{mg} \mathrm{dm}^{-3}$ & $\mathrm{~g} \mathrm{dm}^{-3}$ & & ------ & ----- & $\mathrm{ol}_{\mathrm{C}} \mathrm{dn}$ & ------- & & \\
\hline 5,37 & 58,23 & 14,61 & 22,01 & 5,54 & 2,65 & 0,52 & 0,00 & 3,01 & 8,78 & 11,79 \\
\hline \multicolumn{11}{|c|}{ Características granulométricas } \\
\hline \multicolumn{4}{|c|}{ Argila } & \multicolumn{3}{|c|}{ Silte } & \multicolumn{4}{|c|}{ Areia } \\
\hline \multicolumn{11}{|c|}{ - } \\
\hline \multicolumn{4}{|c|}{522} & \multicolumn{3}{|c|}{364} & \multicolumn{4}{|c|}{114} \\
\hline
\end{tabular}

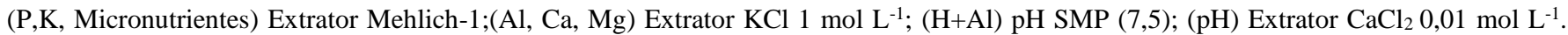
Análise realizada no Laboratório de Química Agrícola e Ambiental, Unioeste. Campus Marechal Cândido Rondon, PR. Fonte: Autores. 
Tabela 2. Características químicas e granulométricas do solo coletado na camada de 0,0-0,2 m proveniente da propriedade Mosconi, localizada no município de Palotina/PR, 2017/2018.

\begin{tabular}{|c|c|c|c|c|c|c|c|c|c|c|}
\hline \multicolumn{11}{|c|}{ Características químicas (b) } \\
\hline $\mathrm{H}$ & $\mathrm{V}$ & $\mathrm{P}$ & MO & $\mathrm{Ca}^{2+}$ & $\mathrm{Mg}^{2+}$ & $\mathrm{K}^{+}$ & $\mathrm{Al}^{3+}$ & $\mathrm{H}+\mathrm{Al}$ & $\mathrm{SB}$ & CTC \\
\hline $\mathrm{CaCl}_{2}$ & $-\%-$ & $\mathrm{mg} \mathrm{dm}{ }^{-3}$ & $\mathrm{~g} \mathrm{dm}^{-3}$ & \multicolumn{7}{|c|}{---------------------- $\mathrm{cmol}_{\mathrm{c}} \mathrm{dm}^{-3}$---------------------- } \\
\hline 5,68 & 61,91 & 12,56 & 20,29 & 4,75 & 2,09 & 1,01 & 0,01 & 4,38 & 7,91 & 9,42 \\
\hline \multicolumn{11}{|c|}{ Características granulométricas } \\
\hline \multicolumn{4}{|c|}{ Argila } & \multicolumn{3}{|c|}{ Silte } & \multicolumn{4}{|c|}{ Areia } \\
\hline \multicolumn{11}{|c|}{---------------------------------------- g Kg } \\
\hline \multicolumn{4}{|c|}{641} & & 298 & & \multicolumn{4}{|c|}{61} \\
\hline
\end{tabular}

(P,K, Micronutrientes) Extrator Mehlich-1;(Al, Ca, Mg) Extrator $\mathrm{KCl} 1 \mathrm{~mol} \mathrm{~L}^{-1}$; (H+Al) pH SMP (7,5); (pH) Extrator CaCl 20,01 mol L-1. Análise realizada no Laboratório de Química Agrícola e Ambiental, Unioeste. Campus Marechal Cândido Rondon/PR. Fonte: Autores.

Tabela 3. Características químicas e granulométricas do solo coletado na camada de 0,0-0,2 m proveniente da propriedade Kestring, localizada no distrito de São Jorge, município de São Miguel do Iguaçu/ PR, 2017/2018.

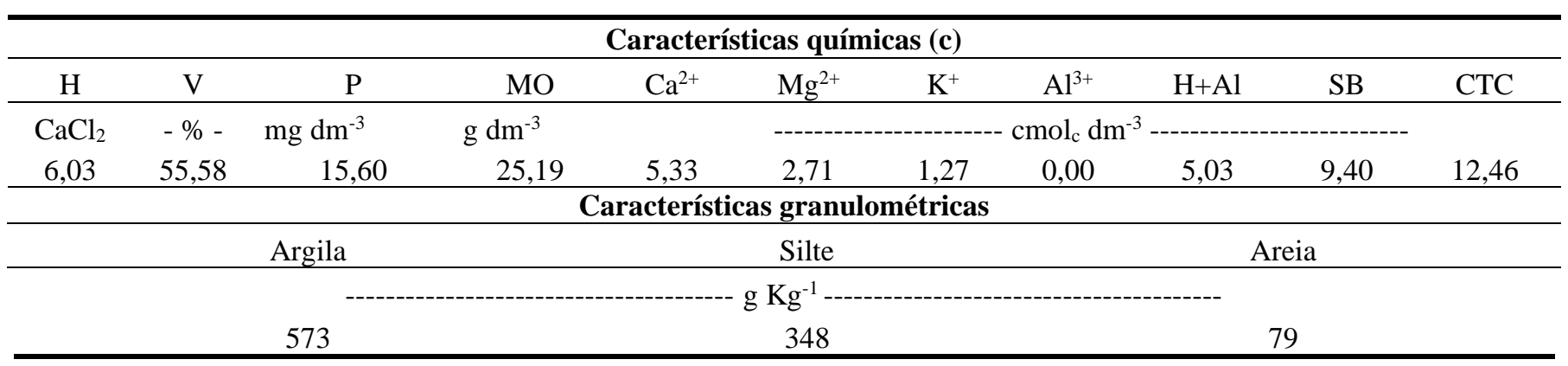

(P,K, Micronutrientes) Extrator Mehlich-1; $\mathrm{Al}, \mathrm{Ca}, \mathrm{Mg}$ ) Extrator $\mathrm{KCl} 1 \mathrm{~mol} \mathrm{~L}{ }^{-1} ;(\mathrm{H}+\mathrm{Al}) \mathrm{pH} \mathrm{SMP} \mathrm{(7,5);} \mathrm{(pH)} \mathrm{Extrator} \mathrm{CaCl}_{2} 0,01 \mathrm{~mol} \mathrm{~L}{ }^{-1}$. Análise realizada no Laboratório de Química Agrícola e Ambiental, Unioeste. Campus Marechal Cândido Rondon/PR. Fonte: Autores.

Tabela 4. Características químicas e granulométricas do solo coletado na camada de 0,0-0,2 m proveniente da propriedade Galeski, localizada no município de Cascavel/PR, 2017/2018.

\begin{tabular}{|c|c|c|c|c|c|c|c|c|c|c|}
\hline \multicolumn{11}{|c|}{ Características químicas (d) } \\
\hline $\mathrm{H}$ & $\mathrm{V}$ & $\mathrm{P}$ & MO & $\mathrm{Ca}^{2+}$ & $\mathrm{Mg}^{2+}$ & $\mathrm{K}^{+}$ & $\mathrm{Al}^{3+}$ & $\mathrm{H}+\mathrm{Al}$ & SB & CTC \\
\hline $\mathrm{CaCl}_{2}$ & $-\%-$ & $\mathrm{mg} \mathrm{dm}^{-3}$ & $\mathrm{~g} \mathrm{dm}^{-3}$ & \multicolumn{7}{|c|}{ - $\mathrm{cmol}_{\mathrm{c}} \mathrm{dm}^{-3}$} \\
\hline 5,29 & 60,11 & 12,28 & 22,20 & 4,90 & 2,45 & 1,01 & 0,00 & 5,55 & 8,39 & 11,04 \\
\hline \multicolumn{11}{|c|}{ Características granulométricas } \\
\hline \multicolumn{4}{|c|}{ Argila } & \multicolumn{3}{|c|}{ Silte } & \multicolumn{4}{|c|}{ Areia } \\
\hline \multicolumn{11}{|c|}{ 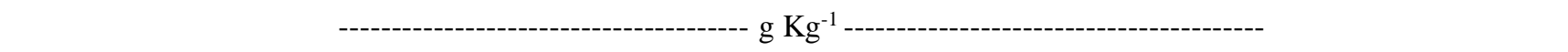 } \\
\hline
\end{tabular}

(P,K, Micronutrientes) Extrator Mehlich-1;(Al, Ca, Mg) Extrator $\mathrm{KCl} 1 \mathrm{~mol} \mathrm{~L} \mathrm{~L}^{-1}$; (H+Al) pH SMP (7,5); (pH) Extrator $\mathrm{CaCl}_{2} 0,01 \mathrm{~mol} \mathrm{~L}{ }^{-1}$. Análise realizada no Laboratório de Química Agrícola e Ambiental, Unioeste. Campus Marechal Cândido Rondon/PR. Fonte: Autores.

Para a classificação de Köppen e Geiger, (1928), a região de São Miguel do Iguaçu possui clima regional Subtropical Úmido Mesotérmico com verões quentes (temperatura média de $20,0^{\circ} \mathrm{C}$ de temperatura e $1755 \mathrm{~mm}$ de pluviosidade, para as respectivas regiões). Quanto às regiões de Toledo, Palotina e Cascavel, estas possuem clima quente e temperado com verões quentes (temperatura média de 19,4; 20,8 e 18,2 ${ }^{\circ} \mathrm{C}$ de temperatura e $1483 ; 1508$ e 1822 mm de pluviosidade, para as respectivas regiões). Independentemente da região, observa-se tendência a concentração de chuvas e 
invernos com geadas pouco frequentes. Os dados meteorológicos das quatro áreas experimentais durante a condução dos experimentos são apresentados nas Figuras 1 A, B, C e D.

Em relação à correção destes solos, quando necessário, foi realizada calagem, 30 dias antes da semeadura, para a elevação da saturação de bases para 70\% conforme Embrapa, (2011). A adubação de base foi realizada segundo a recomendação de Foloni et al. (1974).

Figura 1. Dados médios de pluviosidade, temperatura mínima (...), temperatura média (---) e temperatura máxima ( — ), das diferentes localidades: A) Toledo - PR; B) Palotina - PR; C) São Miguel do Iguaçu - PR e D) Cascavel - PR, durante o período de outubro de 2017 a abril de 2018.
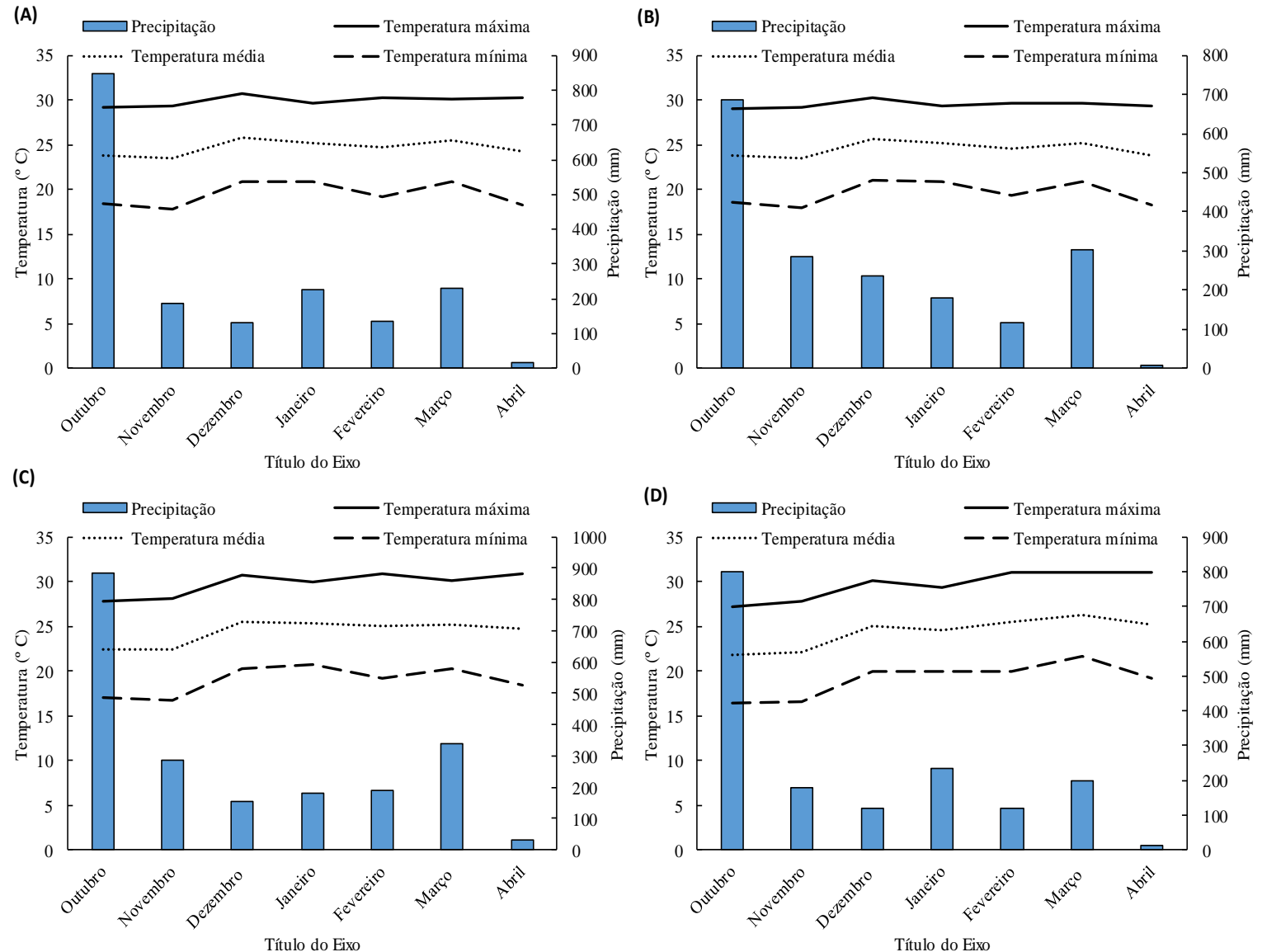

Fonte: Autores.

\section{Número mais provável (NMP) de bactérias diazotróficas endofíticas presentes nos solos das áreas experimentais}

A contagem de microrganismos diazotróficos para determinação da população de bactérias em número de células por $\mathrm{mL}$, foi realizada através da estimativa do número mais provável (NMP) usando a tabela de MacCrady em meio semi-sólido NFB, de acordo com metodologia descrita por Döbereiner et al. (1995).

Os resultados da contagem de microrganismos diazotróficos nos solos dos experimentos, das quatro áreas experimentais, no momento da semeadura apresentavam população de: 1,2 x $10^{5}$ (Toledo/PR); 0,8 x $10^{5}$ (Palotina/PR); 2,7 x $10^{4}$ (São Miguel do Iguaçu/PR) e $0,8 \times 10^{6}$ (Cascavel/PR), Unidade Formadoras de Colônias (UFC) $\mathrm{g}^{-1}$ de bactérias diazotróficas. 
Identificação da amostra de inoculante líquido da empresa FERTIBIO do Brasil, para milho, utilizado nos quatro experimentos

Segundo a empresa FERTIBIO do Brasil, os inoculantes apresentam as seguintes características:

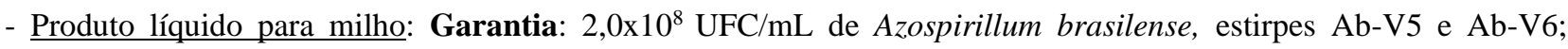
Natureza física: fluida; Densidade: $1,0 \mathrm{~g} / \mathrm{mL}$; Cultura a que se destina: Milho (Zea mays L.); Dosagem testada para $25 \mathrm{~kg}$ de semente: $100 \mathrm{~mL}$.

\section{Identificação da amostra do inoculante Padrão:}

Nos quatro experimentos foram utilizados como referência inoculante padrão devidamente registrado no Ministério da Agricultura, Pecuária e Abastecimento (MAPA), com as seguintes especificações:

- Produto líquido contendo Azospirillum brasilense: Inoculante comercial 'Líquido’ registrado. O inoculante apresenta

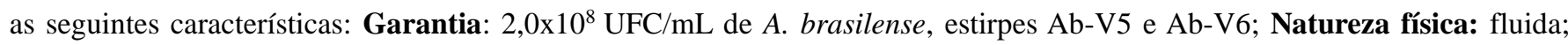
Densidade: $1,0 \mathrm{~g} / \mathrm{mL}$; Cultura a que se destina: Milho (Zea mays L.); Dosagem utilizada no teste/ensaio para 25 kg de semente: $100 \mathrm{~mL}$.

\section{Controle de qualidade dos inoculantes testados}

Os inoculantes da empresa FERTIBIO do Brasil e padrão da empresa ambos utilizados nos quatro experimentos, foram submetidos a testes laboratoriais de concentração (Unidades Formadoras de Colônias), pureza e caracterização. As análises seguiram métodos oficiais, conforme Instrução Normativa n³0, de 12 de novembro de 2010 (MAPA).

Foram obtidos os seguintes resultados quando à concentração das estirpes de bactérias presentes no inoculantes: Inoculante Padrão líquido registrado para milho: $3,07 \times 10^{8} \mathrm{UFC} \mathrm{mL}^{-1}$ (Unidades Formadoras de Colônias); e Inoculante líquido FERTIBIO Azospirillum para milho - $1,16 \times 10^{9} \mathrm{UFC} \mathrm{mL}^{-1}$.

\section{Material vegetal}

Para os quatro experimentos utilizou-se o milho híbrido Piooner® $30 F 53$ YH, o qual apresenta as características de híbrido simples, ciclo precoce (870 unidades de graus dia), grão semiduro amarelo-alaranjado, colmo com alta sanidade e boa resistência ao quebramento; altura 2,20 a 2,40 m; inserção de espiga 1,25 a 1,40 m; folhas semieretas; utilizado para produção de grãos.

\section{Delineamento experimental e tratamentos}

Os quatro ensaios foram conduzidos em delineamento em blocos casualizados com sete tratamentos e quatro repetições, totalizando 24 parcelas experimentais. O ensaio foi constituído dos seguintes tratamentos: $\mathrm{T} 1$ - $0 \mathrm{~kg}$ ha ${ }^{-1}$ de nitrogênio (N), sem inoculação (testemunha); T2 - $80 \mathrm{~kg} \mathrm{ha}^{-1}$ de N, sem inoculação; T3 - $160 \mathrm{~kg} \mathrm{ha}^{-1}$ de N, sem inoculação; T4 - $80 \mathrm{~kg} \mathrm{ha}^{-1} \mathrm{de} \mathrm{N}+$ Inoculação com inoculante 'líquido' padrão registrado, contendo A. brasilense (Ab-V5 e Ab-V6), na dose de $100 \mathrm{~mL} 25 \mathrm{~kg}^{-1}$ de sementes; T5 - $80 \mathrm{~kg} \mathrm{ha}^{-1}$ de $\mathrm{N}+$ inoculação de sementes com inoculante FERTIBIO Azospirillum 'líquido' na dose de $100 \mathrm{~mL} 25 \mathrm{~kg}^{-1}$ de sementes; T6 - $80 \mathrm{~kg} \mathrm{ha}^{-1}$ de $\mathrm{N}+$ inoculação de sementes com inoculante FERTIBIO Azospirillum 'líquido' na dose de $150 \mathrm{~mL} 25 \mathrm{~kg}^{-1}$ de sementes; e $\mathrm{T} 7$ - $80 \mathrm{~kg} \mathrm{ha}{ }^{-1}$ de $\mathrm{N}+$ inoculação de sementes com inoculante FERTIBIO Azospirillum 'líquido’ na dose de $200 \mathrm{~mL} 25 \mathrm{~kg}^{-1}$ de sementes.

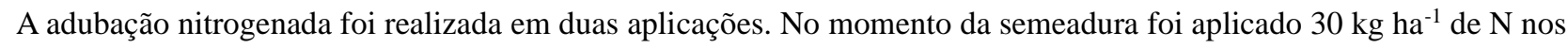
tratamentos, com exceção do T1 (controle). No estádio V6 da cultura do milho foi aplicado $50 \mathrm{~kg} \mathrm{ha}^{-1}$ de $\mathrm{N}$ nos tratamentos que apresentavam dose de $80 \mathrm{~kg} \mathrm{ha}^{-1}$ de $\mathrm{N}$ (T2, T4 e T5), enquanto que para o tratamento T3, foi aplicado $80 \mathrm{~kg}$ ha ${ }^{-1}$ de $\mathrm{N} \mathrm{no}$ 
estádio V4 e $50 \mathrm{~kg} \mathrm{ha}^{-1}$ de $\mathrm{N}$ no estádio V8. A adubação nitrogenada foi realizada com uréia (45\% N) a lanço tanto no momento da semeadura quanto em cobertura.

\section{Implantação e condução do experimento}

Anteriormente à semeadura do milho, as áreas foram dessecadas com herbicida glifosato na dose de 4 L do p.c. ha ${ }^{-1}$. Neste momento foram coletados os restos culturais em 10 pontos de cada área experimental, nas quatro áreas experimentais, com auxílio de um quadrado de metal de 1,0 por $1,0 \mathrm{~m}$, as quais foram pesadas, secas em estufa à $65^{\circ} \mathrm{C}$ e enviadas para análise dos teores de N, P e K nas amostras. Os resultados de produtividade de massa seca da palhada foram: 11,3; 7,8; 9,1 e 5,6 t ha-1 , respectivamente, para as quatro áreas experimentais, nos municípios de Toledo/PR, Palotina/PR, São Miguel do Iguaçu/PR e Cascavel/PR.

De posse dos resultados de produtividade de massa seca da palhada e dos teores de N, na massa seca da palhada, foram efetuados os cálculos de acúmulo nutricional, visando determinar a quantidade de nutrientes $(\mathrm{N}, \mathrm{P}$ e $\mathrm{K})$ acrescida na área pela palhada de cultivos antecessores, cujos resultados foram de 133, 14, $61 \mathrm{~kg} \mathrm{ha}^{-1} \mathrm{de} \mathrm{N}, \mathrm{P}$ e $\mathrm{K}$ para a área experimental de Toledo/PR; 83, 12, 35, $\mathrm{kg} \mathrm{ha}^{-1}$ de N, P e K para a área experimental de Palotina/PR; e 119, 23, 54, kg ha-1 de N, P e K para a área experimental de São Miguel do Iguaçu/PR e 69, 22, 29, $\mathrm{kg}^{-1} \mathrm{a}^{-1}$ de N, P e K para a área experimental de Cascavel/PR, respectivamente.

Os quatro experimentos foram implantados com as seguintes datas de semeadura: Toledo/PR (16 de outubro de 2017), Palotina/PR (30 de outubro de 2017), São Miguel do Iguaçu/PR (25 de outubro de 2017), Cascavel/PR (28 de outubro de 2017).

Anteriormente à inoculação das sementes, estas foram tratadas com fungicida Captan 750 TS na dose de $0,2 \mathrm{~kg} 100$

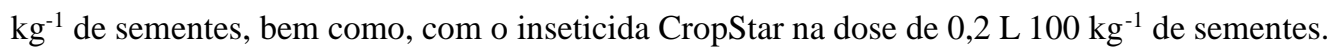

Ainda, anteriormente à semeadura, para a inoculação das sementes foram retiradas alíquotas de inoculantes segundo os cálculos recomendados para cada tratamento, por meio de uma micropipeta modelo Micronam com capacidade de até 10 mL. Foram separados em sacos de plástico de alta densidade 2,0 kg de sementes de milho, onde foi diretamente depositado sobre estas os inoculantes conforme os tratamentos. Em seguida os mesmos foram agitados por aproximadamente dois minutos para uniformizar a distribuição do inoculante nas sementes. Sessenta minutos após a inoculação foi efetuada a semeadura, sendo este o procedimento padrão para os quatro experimentos.

A partir das características químicas do solo e necessidades da cultura foi realizada a adubação fosfatada e potássica no sulco de semeadura com o auxílio de semeadora adubadora mecanizada conforme recomendação (Embrapa, 2012).

A semeadura dos quatro ensaios foi realizada com o auxílio de semeadora manual (matracas), distribuindo-se 5 sementes por metro no sulco de semeadura, tendo alcançado população final de 70.000 plantas ha ${ }^{-1}$. Cada parcela experimental foi constituída de 6 linhas de 0,70 m de espaçamento, com $6 \mathrm{~m}$ de comprimento e 4,2 m de largura, totalizando área de 25,2 m² por parcela, distanciadas entre si por $1 \mathrm{~m}$, e área total de 604,80 $\mathrm{m}^{2}$. Para obtenção da área útil das parcelas foram desconsideradas as linhas laterais externas e 1,0 m das extremidades das linhas de cada parcela. Durante a condução dos experimentos, o controle de plantas daninhas, pragas e doenças foram realizados de acordo com as necessidades da cultura (Embrapa, 2012).

\section{Avaliação morfométricas das plantas no estágio vegetativo}

Para os quatro ensaios, as avaliações morfométricas foram obtidas pela média da avaliação de 10 plantas de milho ao atingirem o estádio fenológico de V10. Foi avaliada a altura da planta (ALT), realizada com o auxílio de uma régua graduada, onde foi definida como sendo à distância do nível do solo até a folha mais alta da planta, expresso em mm; e diâmetro basal do 
colmo (DC), realizado com o auxílio de paquímetro digital, em $\mathrm{mm}$. Em seguida as plantas foram seccionadas na base e separadas em folha e colmo+bainha, Posteriormente, ambas as partes foram acondicionadas separadamente em sacos de papel Kraft devidamente etiquetados e submetidos à secagem em estufa de circulação forçada de ar a $65{ }^{\circ} \mathrm{C}$, até atingirem massa constante. Em seguida, a massa seca das estruturas vegetais foram pesadas em balança de precisão obtendo a massa de matéria seca de folhas (MSF), massa de matéria seca de colmo+bainha (MSCB) e massa de matéria seca total (MST).

\section{Determinação do teor de $\mathbf{N}$ no tecido foliar e nos grãos}

Para os quatro ensaios, no estádio fenológico relativo à emissão da inflorescência feminina, foram coletadas as folhas da região oposta e abaixo da espiga principal de dez plantas de cada parcela útil. As folhas coletadas foram acondicionadas em sacos de papel Kraft e submetidas à secagem em estufa de circulação forçada de ar, a $65{ }^{\circ} \mathrm{C}$, até atingirem massa constante e armazenadas para posterior análise dos teores de $\mathrm{N}$.

Após a colheita das espigas e debulha dos grãos, que será detalhada posteriormente, foram retiradas amostras de grãos correspondentes a cada parcela experimental. Estas amostras foram secas em estufa de circulação forçada de ar a $65{ }^{\circ} \mathrm{C}$ até atingirem massa constante.

As amostras de folhas e grãos foram moídas e submetidas à digestão sulfúrica. Segundo a metodologia da Embrapa (2009) foi realizada a destilação por arraste de vapores, determinando-se então o teor de nitrogênio (N) nos tecidos que foram expressos em $\mathrm{g} \mathrm{kg}^{-1}$ de massa de matéria seca de folha e grão.

\section{Avaliação dos componentes da produção e produtividade}

A colheita dos quatro experimentos foi realizada nas seguintes datas: Município de Toledo/PR (27 de fevereiro de 2018); Palotina/PR (25 de março de 2018); São Miguel do Iguaçu/PR (19 de março de 2018) e Cascavel/PR (23 de março de 2018).

Os componentes da produção foram determinados pela amostragem de dez espigas por parcela útil. As avaliações realizadas foram: comprimento de espiga (CE), expresso em cm, diâmetro de espiga (DE), em mm, número de fileiras de grãos por espiga (NFGE), número de grãos por fileira na espiga (NGF) e massa de mil grãos (MMG), expresso em g.

Para a determinação da produtividade de grãos, as espigas da parcela útil foram trilhadas e os grãos pesados. Aos resultados foram acrescidos a massa de mil grãos das dez espigas utilizadas para avaliação dos componentes de produção, sendo posteriormente transformados em $\mathrm{kg} \mathrm{ha}^{-1}$, corrigindo-se os valores para $13 \%$ de umidade na base úmida.

\section{Análise estatística dos dados}

Os resultados foram submetidos à análise de variância pelo teste de Fisher-Snedecor (teste F) e as médias dos tratamentos foram comparadas pelo teste de Duncan $(\mathrm{p} \leq 0,05)$. As análises foram efetuadas utilizando-se o programa computacional GENES da Universidade Federal de Viçosa (UFV) (Cruz, 2006).

\section{Resultados}

\section{Área experimental do município de Toledo/PR}

Ao avaliar os resultados da análise de variância dos dados referentes ao estádio fenológico V10 na fase vegetativa das plantas de milho híbrido Piooner® 30F53 YH, obtidos para a área do município de Toledo/PR, verifica-se que a altura da planta (ALT), massa seca de colmo+bainha (MSCB) e massa seca total (MST) apresentaram efeitos significativos, em função dos tratamentos, pelo teste $F,(p \leq 0,01)$ (Tabela 5). Quanto ao teor de nitrogênio nas folhas (TEN), este apresentou diferenças pelo teste $\mathrm{F},(\mathrm{p} \leq 0,05)$, no entanto, a variável diâmetro basal do colmo (DCB) não apresentou diferenças entre os tratamentos. 
Research, Society and Development, v. 10, n. 3, e8210311292, 2021

(CC BY 4.0) | ISSN 2525-3409 | DOI: http://dx.doi.org/10.33448/rsd-v10i3.11292

Tabela 5. Resumo da análise de variância e comparação de médias para altura da planta (ALT), diâmetro basal do colmo (DBC), massa de matéria seca de folhas (MSF), massa de matéria seca de colmo+bainha (MSCB), massa de matéria seca total (MST) e teor de nitrogênio nas folhas (TEN), de plantas de milho híbrido cultivar Piooner® 30F53 YH, Município de Toledo/PR, 2017/2018.

\begin{tabular}{|c|c|c|c|c|c|c|}
\hline \multirow{2}{*}{ TRA } & ALT & DCB & MSCB & MSF & MST & TEN \\
\hline & $\mathrm{cm}$ & $\mathrm{Mm}$ & g & G & g & \\
\hline $\mathrm{T} 1$ & $25,33 \mathrm{c}$ & 7,31 & $8,26 \mathrm{~d}$ & $8,91 \mathrm{c}$ & $17,17 \mathrm{c}$ & 2,14 \\
\hline $\mathrm{T} 2$ & $31,48 \mathrm{~b}$ & 7,43 & $10,42 \mathrm{c}$ & $11,17 \mathrm{~b}$ & $21,60 \mathrm{~b}$ & 2,47 bc \\
\hline $\mathrm{T} 3$ & 38,49 a & 8,52 & $12,63 \mathrm{a}$ & 13,48 a & $26,11 \mathrm{a}$ & $2,89 \quad a$ \\
\hline $\mathrm{T} 4$ & $35,68 \mathrm{ab}$ & 8,27 & $11,73 \mathrm{abc}$ & $12,56 \mathrm{ab}$ & $24,29 \mathrm{ab}$ & $2,78 \mathrm{ab}$ \\
\hline T5 & $32,71 \mathrm{~b}$ & 7,69 & $10,97 \mathrm{bc}$ & $11,74 \mathrm{ab}$ & $22,72 \mathrm{ab}$ & $2,54 \mathrm{abc}$ \\
\hline T6 & $36,93 \mathrm{ab}$ & 8,44 & $12,29 \mathrm{ab}$ & $13,13 \mathrm{ab}$ & $25,43 \mathrm{ab}$ & $2,68 \mathrm{ab}$ \\
\hline $\mathrm{T} 7$ & $35,54 \mathrm{ab}$ & 8,11 & $12,38 \mathrm{ab}$ & $13,19 \mathrm{ab}$ & $25,58 \mathrm{ab}$ & $2,71 \mathrm{ab}$ \\
\hline C.V. & 22,26 & 13,19 & 19,45 & 17,32 & 16,21 & 13,57 \\
\hline D.M.S. & 5,11 & 1,284 & 1,63 & 2,23 & 4,42 & 0,41 \\
\hline F. & $6,78^{* *}$ & $1,23^{\mathrm{ns}}$ & $9,82^{* *}$ & $5,06^{* *}$ & $12,91^{* *}$ & $1,12^{*}$ \\
\hline
\end{tabular}

Não significativo (ns), ou significativo a $10(*)$ e $5 \%(* *)$, respectivamente pelo teste F. Médias seguidas de mesma letra minúscula na coluna, não diferem estatisticamente entre si pelo teste de Tukey $(\mathrm{p} \leq 0,05)$. C.V. Coeficiente de variação; D.M.S. Desvio mínimo significativo; F Calculado. T1 - $0 \mathrm{~kg} \mathrm{ha}^{-1}$ de nitrogênio $(\mathrm{N})$, sem inoculação (testemunha); T2 - $80 \mathrm{~kg} \mathrm{ha}^{-1}$ de N, sem inoculação; T3 - $160 \mathrm{~kg}$ $\mathrm{ha}^{-1}$ de $\mathrm{N}$, sem inoculação; $\mathbf{T} 4-80 \mathrm{~kg} \mathrm{ha}^{-1}$ de $\mathrm{N}$ + Inoculação com inoculante líquido registrado, contendo A. brasilense (Ab-V5 e Ab-V6), na dose de $100 \mathrm{~mL} 25 \mathrm{~kg}^{-1}$ de sementes; $\mathbf{T} 5-80 \mathrm{~kg} \mathrm{ha}^{-1} \mathrm{de} \mathrm{N}+$ inoculação de sementes com inoculante FERTIBIO Azospirillum 'Líquido' na dose de $100 \mathrm{~mL} 25 \mathrm{~kg}^{-1}$ de sementes; T6 - $80 \mathrm{~kg} \mathrm{ha}^{-1}$ de $\mathrm{N}+$ inoculação de sementes com inoculante FERTIBIO Azospirillum 'Líquido' na dose de $150 \mathrm{~mL} 25 \mathrm{~kg}^{-1}$ de sementes. T7 - $80 \mathrm{~kg} \mathrm{ha}^{-1}$ de N + inoculação de sementes com inoculante FERTIBIO Azospirillum 'Líquido'

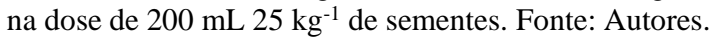

A altura da planta de milho foi superior no tratamento com fornecimento da dose cheia $160 \mathrm{~kg} \mathrm{ha}^{-1} \mathrm{de} \mathrm{N}$, sem a presença de inoculação (T3), superando em 51,95\% o T1, seguido pelos tratamentos T2 e T6, que superaram em $22,27 \%$ e 17,67 \% o T1, respectivamente (Tabela 5). Quanto à massa de matéria seca de folhas de milho (MSF), esta foi superior no T3, superando em 52,96\% o T1, seguido pelo tratamento T2, superando em 21,14\% (Tabela 5). Os tratamentos T5 e T6 apresentaram superioridade em relação ao tratamento T2 em 17,90\% e 18,78\%, respectivamente (Tabela 5).

A massa de matéria seca de colmo+bainha (MSCB) foi superior no T3, superando em 52,96\% o T1, seguido pelo tratamento T2, superando em 21,14\% (Tabela 5). Os tratamentos T5 e T6 apresentaram superioridade em relação ao tratamento T2 em $17,90 \%$ e $18,78 \%$, respectivamente (Tabela 5). 
Tabela 6. Resumo da análise de variância e comparação de médias para comprimento de espiga (CE), diâmetro de espiga (DE), número de fileiras de grãos por espiga (NFGE), número de grãos por fileira na espiga (NGF), número total de grãos por espiga (NG) e massa de mil grãos (MMG), de plantas de milho híbrido cultivar Piooner@ 30F53 YH, município de Toledo/PR, $2017 / 2018$.

\begin{tabular}{ccccccc}
\hline & CE & DE & NFGE & NGF & NG & MMG \\
\cline { 2 - 6 } TRA & $\mathrm{cm}$ & Mm & & & & $\mathrm{g}$ \\
\hline T1 & $17,72 \mathrm{c}$ & $7,24 \mathrm{c}$ & $15,80 \mathrm{~b}$ & $30,02 \mathrm{c}$ & $474,31 \mathrm{c}$ & $162,81 \mathrm{~b}$ \\
T2 & $19,01 \mathrm{bc}$ & $8,47 \mathrm{~b}$ & $16,75 \mathrm{ab}$ & $31,81 \mathrm{bc}$ & $533,05 \mathrm{bc}$ & $167,35 \mathrm{~b}$ \\
T3 & $22,64 \mathrm{a}$ & $9,67 \mathrm{a}$ & $18,01 \mathrm{a}$ & $37,64 \mathrm{a}$ & $677,28 \mathrm{a}$ & $192,21 \mathrm{a}$ \\
T4 & $21,87 \mathrm{a}$ & $9,23 \mathrm{ab}$ & $17,34 \mathrm{ab}$ & $35,35 \mathrm{ab}$ & $612,02 \mathrm{ab}$ & $185,74 \mathrm{a}$ \\
T5 & $20,28 \mathrm{ab}$ & $8,80 \mathrm{ab}$ & $17,38 \mathrm{ab}$ & $33,98 \mathrm{abc}$ & $591,47 \mathrm{ab}$ & $177,66 \mathrm{ab}$ \\
T6 & $22,31 \mathrm{a}$ & $9,23 \mathrm{ab}$ & $17,81 \mathrm{a}$ & $37,38 \mathrm{a}$ & $666,81 \mathrm{a}$ & $186,14 \mathrm{a}$ \\
T7 & $20,90 \mathrm{ab}$ & $9,24 \mathrm{ab}$ & $17,41 \mathrm{ab}$ & $35,44 \mathrm{ab}$ & $617,09 \mathrm{ab}$ & $188,68 \mathrm{a}$ \\
\hline C.V. & 14,92 & 15,30 & 14,56 & 15,93 & 17,73 & 19,21 \\
D.M.S. & 2,38 & 1,08 & 1,83 & 4,78 & 107,63 & 15,07 \\
F. & $12,67^{* *}$ & $11,72^{* *}$ & $3,58^{*}$ & $7,55^{* *}$ & $9,78^{* *}$ & $6,46^{* *}$
\end{tabular}

Não significativo (ns), ou significativo a $10\left(^{*}\right)$ e $5 \%(* *)$, respectivamente pelo teste $\mathrm{F}$. Médias seguidas de mesma letra minúscula na coluna, não diferem estatisticamente entre si pelo teste de Tukey $(\mathrm{p} \leq 0,05)$. C.V. Coeficiente de variação; D.M.S. Desvio mínimo significativo; F Calculado. T1 - 0 kg ha-1 de nitrogênio (N), sem inoculação (testemunha); T2 - 80 kg ha-1 de N, sem inoculação; T3 - 160 kg ha-1 de N, sem inoculação; T4 - 80 kg ha-1 de N + Inoculação com inoculante líquido registrado, contendo A. brasilense (Ab-V5 e AbV6), na dose de $100 \mathrm{~mL} 25 \mathrm{~kg}-1$ de sementes; T5 - $80 \mathrm{~kg}$ ha-1 de N + inoculação de sementes com inoculante FERTIBIO Azospirillum 'Líquido' na dose de $100 \mathrm{~mL} 25 \mathrm{~kg}-1$ de sementes; T6 - $80 \mathrm{~kg}$ ha-1 de N + inoculação de sementes com inoculante FERTIBIO Azospirillum 'Líquido' na dose de $150 \mathrm{~mL} 25 \mathrm{~kg}-1$ de sementes. T7 - $80 \mathrm{~kg}$ ha-1 de $\mathrm{N}+$ inoculação de sementes com inoculante FERTIBIO Azospirillum 'Líquido' na dose de $200 \mathrm{~mL} 25 \mathrm{~kg}-1$ de sementes. Fonte: Autores.

A matéria seca de folha (MSF) foi superior no T3, superando em 51,33\% o T1, seguido pelo tratamento T2, superando em 20,71\% (Tabela 5). De modo geral todos os tratamentos que receberam 50\% da recomendação de nitrogênio T4, T5, T6 e T7, associado à microrganismo promotores de crescimento não diferenciaram ao tratamento T3 (Tabela 5). A matéria seca de folha (MSF) foi superior no T3, superando em 58,10\% o T1 e T2 em 20,92\% (Tabela 5). O teor de nitrogênio nas folhas de milho (TEN) foi superior no T3, superando em 35,05\% o T1, seguido pelo tratamento T2 em 17,00\% (Tabela 5).

Para os componentes da produção de milho da referida cultivar as variáveis diâmetro de espiga (DE, em mm), número de grãos por fileira na espiga (NGF), número total de grão por espiga (NG) e massa de mil grãos (MMG, em gramas), apresentaram efeitos significativos pelo teste $\mathrm{F},(\mathrm{p} \leq 0,01)$ (Tabela 6). Já o número de fileiras de grãos por espiga (NFGE) apresentou diferenças pelo teste $\mathrm{F},(\mathrm{p} \leq 0,05)$, e comprimento de espiga $(\mathrm{CE})$ não apresentou diferenças entre os tratamentos, na mesma tabela.

O comprimento de espiga de milho híbrido cultivar Piooner® 30F53 YH (CE) foi superior no T3, superando em o T1 e o T2, seguido pelos tratamentos T4 e T6, que superaram em 15,04\% e 1,36 o T1, respectivamente (Tabela 6). De modo geral todos os tratamentos que recebera a metade da dose recomendada que receberam microrganismo promotores de crescimento não diferiram do tratamento com 100\% da recomendação agronômica referente ao nitrogênio (Tabela 6).

O diâmetro de espiga (DE, em mm) foi superior no T3, superando em 33,56\% o T1 e 14,17\% o T2. Todos os tratamentos que receberam a presença de inoculação com A. brasilense não diferenciaram do tratamento com $100 \%$ da recomendação de nitrogênio (T3) (Tabela 6).

O número de fileiras de grãos por espiga (NFGE) foi superior no T3, superando em 13,99\% o T1, seguido pelos tratamentos T6, que superaram em 12,72\% o T1. Para o número de grãos por fileira na espiga (NGF) esta variável foi superior no T3, superando em $25,38 \%$ o T1 e $18,33 \%$ o T2, seguido pelos tratamentos T6, que superaram em $24,52 \%$ o T1 e $17,51 \%$ o $\mathrm{T} 2$, respectivamente (Tabela 6). 
O número total de grãos por espiga (NG) foi superior no T3, superando em 42,79\% o T1 e 27,06\% o T2, seguido pelos tratamentos T6, que superaram em 40,59\% o T1 e 25,09\% o T2, respectivamente. A massa de mil grãos (MMG, em gramas) foi superior no T3, superando em 18,06\% o T1 e 14,86\% o T2, seguido pelos tratamentos T4, que superaram em $14,08 \%$ o T1 e 10,99\% o T2, seguido pelo tratamento T6, que superaram em 14,33\% o T1 e seguido pelos tratamentos T7, que superaram em $15,89 \%$ o T1 e $12,75 \%$ o T2 (Tabela 6 ).

A produtividade foi superior no tratamento T3, superando em 98,39\% o T1 e 5,86\% o T2, seguido pelos tratamentos T4, T5, T6 e T7, que superaram em 61,03\%, 76,16\%, 776,23\% e 77,47\%, o T1, respectivamente (Figura 2). Todos os tratamentos inoculados com A. brasilense não diferenciaram do tratamento T3 (100\% de N) (Figura 2).

Figura 2. Produtividade de plantas de milho híbrido cultivar Piooner ${ }^{\circledR} 30 \mathrm{~F} 53 \mathrm{YH}$ cultivadas sobre diferentes formas de inoculação de sementes com bactérias diazotróficas, no município de Toledo/PR Médias seguidas das mesmas letras minúsculas na coluna não diferem entre si pelo teste de Tukey a $1 \%$. CV =18,99\%; DMS = 1630,84; e F cal = 8,59. T1 - $0 \mathrm{~kg}$ $\mathrm{ha}^{-1}$ de nitrogênio (N), sem inoculação (testemunha); T2 - $80 \mathrm{~kg} \mathrm{ha}^{-1}$ de N, sem inoculação; T3 - $160 \mathrm{~kg} \mathrm{ha}{ }^{-1}$ de $\mathrm{N}$, sem inoculação; T4 - $80 \mathrm{~kg} \mathrm{ha}^{-1}$ de N + Inoculação com inoculante líquido registrado, contendo A. brasilense (Ab-V5 e Ab-V6), na dose de $100 \mathrm{~mL} 25 \mathrm{~kg}^{-1}$ de sementes; T5 - $80 \mathrm{~kg} \mathrm{ha}^{-1}$ de $\mathrm{N}+$ inoculação de sementes com inoculante FERTIBIO Azospirillum 'Líquido' na dose de $100 \mathrm{~mL} 25 \mathrm{~kg}^{-1}$ de sementes; T6 - $80 \mathrm{~kg} \mathrm{ha}^{-1}$ de $\mathrm{N}+$ inoculação de sementes com inoculante FERTIBIO Azospirillum 'Líquido' na dose de $150 \mathrm{~mL} 25 \mathrm{~kg}^{-1}$ de sementes. T7 - 80 kg ha-1 de $\mathrm{N}+$ inoculação de sementes com inoculante FERTIBIO Azospirillum 'Líquido' na dose de $200 \mathrm{~mL} 25 \mathrm{~kg}^{-1}$ de sementes.

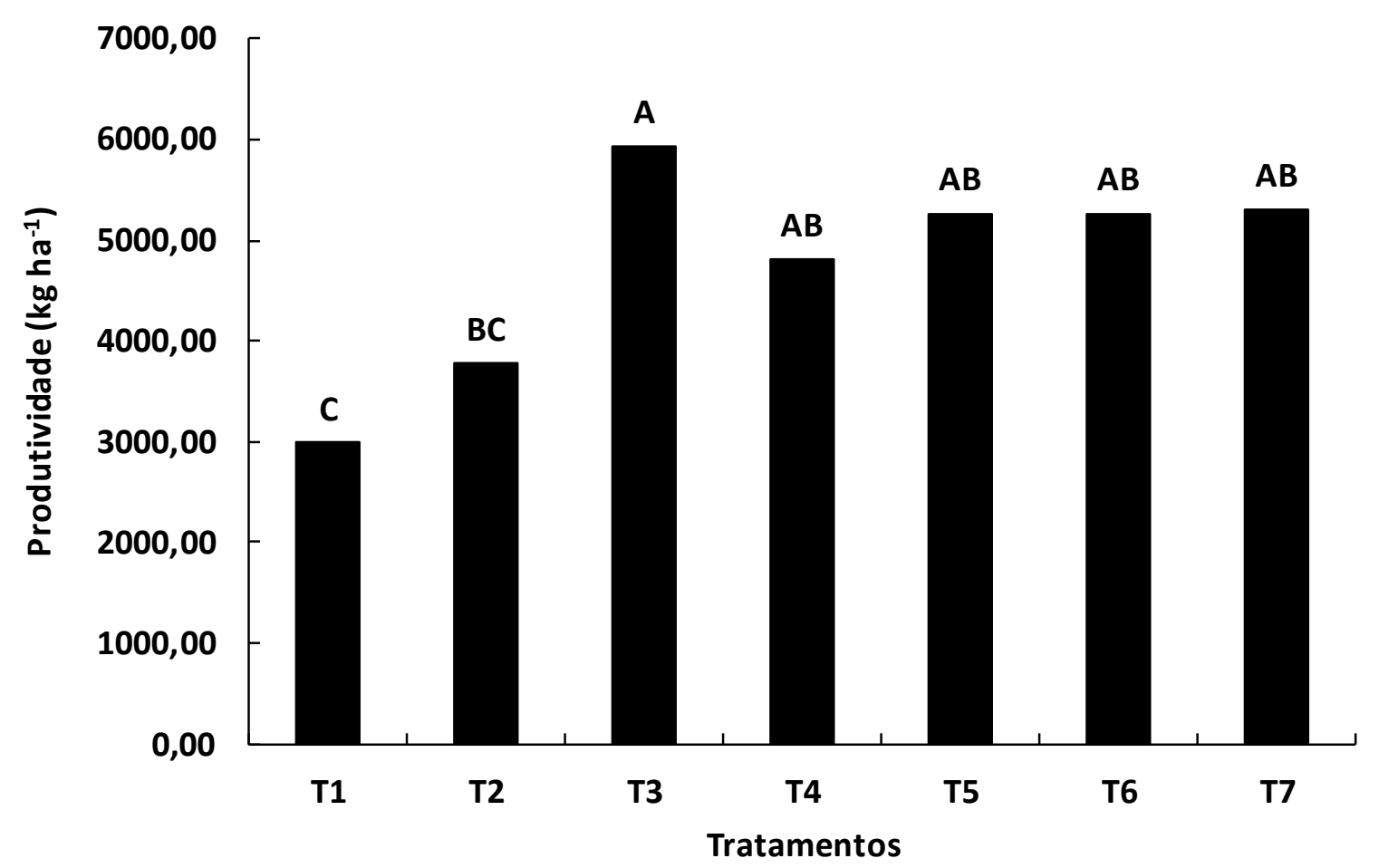

Fonte: Autores.

\section{Área experimental no município de Palotina/PR}

Ao avaliar os resultados da análise de variância dos dados referentes a fase fenológico vegetativa V10 das plantas de milho híbrido Piooner® 30F53 YH, obtidos para a área do município de Palotina/PR. Verifica-se que às variáveis massa seca de colmo+bainha (MSCB) massa seca de folha (MSF), massa seca total (MST), e teor de nitrogênio foliar (TEN) apresentaram 
diferenças pelo teste $\mathrm{F},(\mathrm{p} \leq 0,01)$ (Tabela 7). Já a variável altura da planta (ALT) apresentou efeito significativos pelo teste $\mathrm{F}$, $(\mathrm{p} \leq 0,05)$. Por outro lado, a variável diâmetro basal do colmo (DCB) não apresentou diferenças entre os tratamentos (Tabela 7).

Tabela 7. Resumo da análise de variância e comparação de médias para altura da planta (ALT), diâmetro basal do colmo (DBC), massa de matéria seca de folhas (MSF), massa de matéria seca de colmo+bainha (MSCB), massa de matéria seca total (MST) e teor de nitrogênio foliar (TEN), de plantas de milho híbrido cultivar Piooner® 30F53 YH, município de Toledo/PR, $2017 / 2018$.

\begin{tabular}{ccccccc}
\hline & ALT & DCB & MSCB & MSF & MST & TEN \\
\cline { 2 - 6 } TRA & $\mathrm{cm}$ & Mm & $\mathrm{g}$ & $\mathrm{g}$ & $\mathrm{g}$ & \\
\hline T1 & $18,63 \mathrm{~b}$ & $6,51 \mathrm{c}$ & $5,05 \mathrm{~b}$ & $4,64 \mathrm{c}$ & $9,70 \mathrm{c}$ & $1,85 \mathrm{~b}$ \\
T2 & $28,56 \mathrm{ab}$ & $6,84 \mathrm{c}$ & $5,96 \mathrm{a}$ & $5,83 \mathrm{bc}$ & $11,79 \mathrm{~b}$ & $2,17 \mathrm{ab}$ \\
T3 & $36,24 \mathrm{a}$ & $8,35 \mathrm{ab}$ & $6,32 \mathrm{a}$ & $8,29 \mathrm{a}$ & $14,62 \mathrm{a}$ & $2,58 \mathrm{a}$ \\
T4 & $31,53 \mathrm{a}$ & $7,45 \mathrm{bc}$ & $6,03 \mathrm{a}$ & $6,24 \mathrm{abc}$ & $12,27 \mathrm{~b}$ & $2,23 \mathrm{ab}$ \\
T5 & $29,97 \mathrm{ab}$ & $8,42 \mathrm{ab}$ & $5,78 \mathrm{ab}$ & $5,86 \mathrm{bc}$ & $11,64 \mathrm{bc}$ & $2,28 \mathrm{a}$ \\
T6 & $32,61 \mathrm{a}$ & $8,53 \mathrm{a}$ & $6,27 \mathrm{a}$ & $7,36 \mathrm{ab}$ & $13,63 \mathrm{ab}$ & $2,31 \mathrm{a}$ \\
T7 & $31,48 \mathrm{a}$ & $7,92 \mathrm{ab}$ & $6,21 \mathrm{a}$ & $7,03 \mathrm{ab}$ & $13,24 \mathrm{ab}$ & $2,26 \mathrm{ab}$ \\
\hline C.V. & 13,63 & 25,12 & 24,37 & 12,98 & 18,68 & 24,73 \\
D.M.S. & 12,54 & 1,07 & 0,82 & 2,26 & 2,04 & 0,41 \\
F. & $5,04^{*}$ & $2,77^{\mathrm{ns}}$ & $7,41^{* *}$ & $6,82^{* *}$ & $8,25^{* *}$ & $3,92^{* *}$ \\
\hline
\end{tabular}

Não significativo (ns), ou significativo a $10\left(^{*}\right)$ e $5 \%(* *)$, respectivamente pelo teste F. Médias seguidas de mesma letra minúscula na coluna, não diferem estatisticamente entre si pelo teste de Tukey $(p \leq 0,05)$. C.V. Coeficiente de variação; D.M.S. Desvio mínimo significativo; F Calculado. T1 - $0 \mathrm{~kg} \mathrm{ha}^{-1}$ de nitrogênio (N), sem inoculação (testemunha); T2 - $80 \mathrm{~kg} \mathrm{ha}^{-1} \mathrm{de} \mathrm{N}$, sem inoculação; T3 - $160 \mathrm{~kg}$ ha ${ }^{-1}$ de N, sem inoculação; $\mathbf{T} 4-80 \mathrm{~kg} \mathrm{ha}^{-1}$ de $\mathrm{N}$ + Inoculação com inoculante líquido registrado, contendo A. brasilense (Ab-V5 e Ab-V6), na dose de $100 \mathrm{~mL} 25 \mathrm{~kg}^{-1}$ de sementes; $\mathbf{T 5}$ - $80 \mathrm{~kg} \mathrm{ha}^{-1}$ de $\mathrm{N}+$ inoculação de sementes com inoculante FERTIBIO Azospirillum 'Líquido' na dose de $100 \mathrm{~mL} 25 \mathrm{~kg}^{-1}$ de sementes; T6 - $80 \mathrm{~kg} \mathrm{ha}^{-1}$ de $\mathrm{N}+$ inoculação de sementes com inoculante FERTIBIO Azospirillum 'Líquido' na dose de $150 \mathrm{~mL} 25 \mathrm{~kg}^{-1}$ de sementes. T7 - $80 \mathrm{~kg} \mathrm{ha}^{-1} \mathrm{de} \mathrm{N}+$ inoculação de sementes com inoculante FERTIBIO Azospirillum 'Líquido'

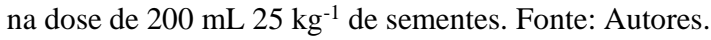

A altura da planta de milho foi superior no tratamento T3, superando em 94,52\% o T1, seguido pelos tratamentos T4, T6 e T7, que superaram em 14,94\%, 11,13\% e 15,12\% o T1, respectivamente. Quanto à massa de matéria seca de colmo+bainha (MSCB), esta foi superior no T3, superando em 25,15\% o T1, seguido pelo tratamento T2, T4, T6 e T7 superando em 18,02\%, 19,41\%, 24,16\% e 22,9\% o T1, respectivamente (Tabela 7).

A massa de matéria seca de folhas (MSF) foi superior no T3, superando em 78,66\%, 42,20\% e 41,47\% os tratamentos T1, T2 e T5, respectivamente. No caso da matéria seca total (MST) verificou-se superioridade para T3, que superou em 50,2\%, $24,00 \%, 19,15 \%$ e 25,60\% os tratamentos T1, T2, T4 e T5, respectivamente. Quanto ao teor de nitrogênio nas folhas de milho (TEN) este foi superior para o tratamento T3, superando em 39,46\% o T1, seguidos pelos tratamentos T5 e T6 em $23,24 \%$ e $24,86 \%$, respectivamente (Tabela 7 ). 
Tabela 8. Resumo da análise de variância e comparação de médias para comprimento de espiga (CE), diâmetro de espiga (DE), número de fileiras de grãos por espiga (NFGE), número de grãos por fileira na espiga (NGF), número total de grãos por espiga (NG) e massa de mil grãos (MMG), de plantas de milho híbrido Piooner® 30F53 YH, município de Palotina/PR, $2017 / 2018$.

\begin{tabular}{ccccccc}
\hline & CE & DE & NFGE & NGF & NG & MMG \\
\cline { 2 - 6 } TRA & $\mathrm{cm}$ & $\mathrm{mm}$ & & & & $\mathrm{g}$ \\
\hline T1 & $10,60 \mathrm{~b}$ & $5,92 \mathrm{c}$ & $11,50 \mathrm{c}$ & $21,25 \mathrm{~b}$ & $244,38 \mathrm{c}$ & $123,32 \mathrm{c}$ \\
T2 & $13,03 \mathrm{a}$ & $6,25 \mathrm{bc}$ & $13,50 \mathrm{~b}$ & $23,52 \mathrm{ab}$ & $317,52 \mathrm{~b}$ & $134,28 \mathrm{bc}$ \\
T3 & $14,04 \mathrm{a}$ & $6,71 \mathrm{a}$ & $14,75 \mathrm{a}$ & $26,03 \mathrm{a}$ & $383,94 \mathrm{a}$ & $159,41 \mathrm{a}$ \\
T4 & $13,82 \mathrm{a}$ & $6,57 \mathrm{ab}$ & $15,00 \mathrm{a}$ & $25,51 \mathrm{a}$ & $382,65 \mathrm{a}$ & $138,32 \mathrm{abc}$ \\
T5 & $14,11 \mathrm{a}$ & $6,60 \mathrm{a}$ & $14,50 \mathrm{ab}$ & $24,75 \mathrm{a}$ & $358,88 \mathrm{ab}$ & $136,10 \mathrm{bc}$ \\
T6 & $14,42 \mathrm{a}$ & $6,61 \mathrm{a}$ & $15,25 \mathrm{a}$ & $25,03 \mathrm{a}$ & $381,71 \mathrm{a}$ & $149,22 \mathrm{ab}$ \\
T7 & $13,80 \mathrm{a}$ & $6,48 \mathrm{ab}$ & $15,25 \mathrm{a}$ & $25,04 \mathrm{a}$ & $381,86 \mathrm{a}$ & $145,18 \mathrm{ab}$ \\
\hline C.V. & 15,98 & 13,22 & 13,31 & 15,58 & 16,89 & 17,04 \\
D.M.S. & 1,88 & 0,51 & 1,10 & 3,19 & 56,32 & 21,27 \\
F. & $11,17^{* *}$ & $14,72^{* *}$ & $33,00^{* *}$ & $5,50^{* *}$ & $18,90^{* *}$ & $4,22^{* *}$ \\
\hline
\end{tabular}

Não significativo (ns), ou significativo a $10(*)$ e $5 \%(* *)$, respectivamente pelo teste F. Médias seguidas de mesma letra minúscula na coluna, não diferem estatisticamente entre si pelo teste de Tukey $(p \leq 0,05)$. C.V. Coeficiente de variação; D.M.S. Desvio mínimo significativo; F Calculado. T1 - $0 \mathrm{~kg} \mathrm{ha}^{-1}$ de nitrogênio (N), sem inoculação (testemunha); T2 - $80 \mathrm{~kg} \mathrm{ha}^{-1}$ de N, sem inoculação; T3 - $160 \mathrm{~kg}$ ha ${ }^{-1}$ de N, sem inoculação; $\mathbf{T} 4-80 \mathrm{~kg} \mathrm{ha}^{-1}$ de $\mathrm{N}$ + Inoculação com inoculante líquido registrado, contendo A. brasilense (Ab-V5 e Ab-V6), na dose de $100 \mathrm{~mL} 25 \mathrm{~kg}^{-1}$ de sementes; $\mathbf{T 5}$ - $80 \mathrm{~kg} \mathrm{ha}^{-1}$ de $\mathrm{N}+$ inoculação de sementes com inoculante FERTIBIO Azospirillum 'Líquido' na dose de $100 \mathrm{~mL} 25 \mathrm{~kg}^{-1}$ de sementes; T6 - $80 \mathrm{~kg} \mathrm{ha}^{-1} \mathrm{de} \mathrm{N}+$ inoculação de sementes com inoculante FERTIBIO Azospirillum 'Líquido' na dose de $150 \mathrm{~mL} 25 \mathrm{~kg}^{-1}$ de sementes. T7 - $80 \mathrm{~kg} \mathrm{ha}^{-1}$ de $\mathrm{N}+$ inoculação de sementes com inoculante FERTIBIO Azospirillum 'Líquido'

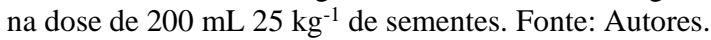

Todos as variáveis que fazem parte dos componentes da produção do milho híbrido Piooner® $30 \mathrm{~F} 53$ YH, comprimento de espiga (CE em cm), diâmetro de espiga (DE, em mm), o número de fileiras de grãos por espiga (NFGE), número de grãos por fileira na espiga (NGF), número total de grão por espiga (NG) e massa de mil grãos (MMG, em gramas), apresentaram efeitos significativos pelo teste $\mathrm{F},(\mathrm{p} \leq 0,01)$ (Tabela 8$)$.

O comprimento de espiga (CE), instalado na área experimental de Palotina demonstrou que todos os tratamentos foram superiores ao tratamento T1 para o diâmetro de espiga (DE, em mm), verificou-se superioridade para o tratamento T3, superando em 13,34\% o T1 e 7,36\% o T2. Em seguida os tratamentos T5 e T6 superaram os tratamentos T1 em 11,49\% e $11,66 \%$ e T2 em 5,60\% e 5,76\%, respectivamente (Tabela 8 ).

O número de fileiras de grãos por espiga (NFGE) foi superior nos tratamentos T5 e T6, superando em 32,61\% o T1 e $12,96 \%$ o T2. Em seguida os tratamentos T4 e T3 superaram os tratamentos T1 em 30,43\% e 28,26\% e T2 em 11,11\% e 9,26\%, respectivamente. Quanto ao número de grãos por fileira na espiga (NGF), esta variável foi inferior no T1, comparado a todos os demais tratamentos com exceção de T2. A maior diferença foi observada foi de 22,49\% entre os tratamentos T3 e T1 (Tabela 8).

O e número total de grãos por espiga (NG) foi superior no T3, superando em 20,92\% o T1 e 57,11\% o T2, seguido pelos tratamentos T4, T5 e T6 que superaram em 20,51\%, 20,26\% e 20,22 o T1 e 566,58\%, 56,26\% e 56,20\% o T2, respectivamente. Avaliando-se a massa de mil grãos (MMG) constata-se superioridade para o tratamento T3, superando em $29,27 \%$ o T1 e $18,71 \%$ o T2 (Tabela 8 ). 
Figura 3. Produtividade de plantas de milho híbrido cultivar Piooner® 30F53 YH cultivadas sobre diferentes formas de inoculação de sementes com bactérias diazotróficas, no município de Palotina/PR Médias seguidas das mesmas letras minúsculas na coluna não diferem entre si pelo teste de Tukey a 5\%. CV =12,03\%; DMS = 987,91; e F cal = 48,04. T1 - 0 kg ha ${ }^{-1}$ de nitrogênio $(\mathrm{N})$, sem inoculação (testemunha); T2 - $80 \mathrm{~kg} \mathrm{ha}^{-1}$ de $\mathrm{N}$, sem inoculação; T3 - $160 \mathrm{~kg}$ ha ${ }^{-1}$ de $\mathrm{N}$, sem inoculação; T4 - 80 kg ha-1 de N + Inoculação com inoculante líquido registrado, contendo A. brasilense (Ab-V5 e Ab-V6), na dose de $100 \mathrm{~mL} 25 \mathrm{~kg}^{-1}$ de sementes; T5 - $80 \mathrm{~kg} \mathrm{ha}^{-1}$ de $\mathrm{N}+$ inoculação de sementes com inoculante FERTIBIO Azospirillum 'Líquido' na dose de $100 \mathrm{~mL} 25 \mathrm{~kg}^{-1}$ de sementes; T6 - $80 \mathrm{~kg} \mathrm{ha}^{-1}$ de $\mathrm{N}+$ inoculação de sementes com inoculante FERTIBIO Azospirillum 'Líquido' na dose de $150 \mathrm{~mL} 25 \mathrm{~kg}^{-1}$ de sementes. T7 - $80 \mathrm{~kg} \mathrm{ha}^{-1}$ de $\mathrm{N}+$ inoculação de sementes com inoculante FERTIBIO Azospirillum 'Líquido' na dose de $200 \mathrm{~mL} 25 \mathrm{~kg}^{-1}$ de sementes.

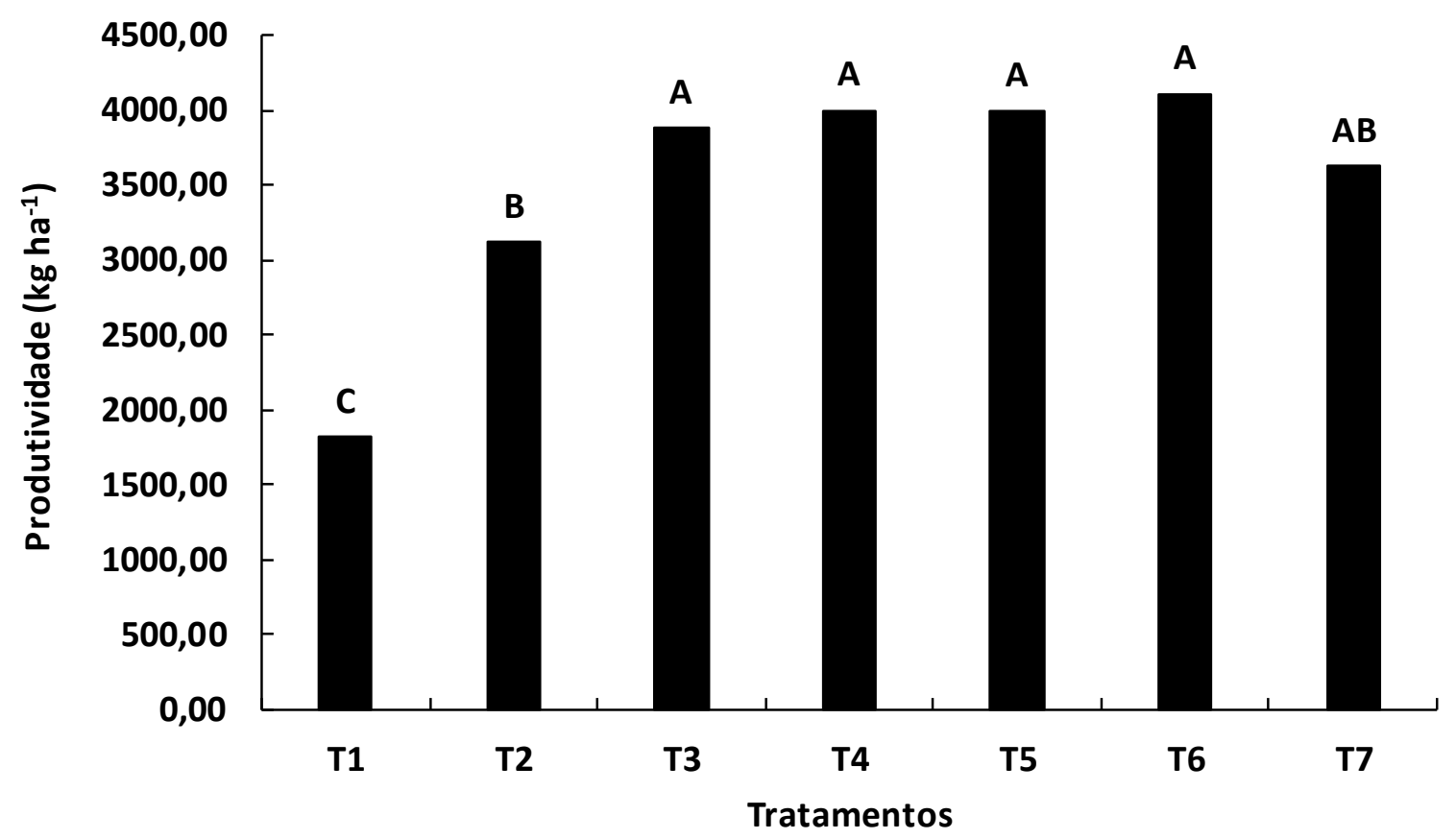

Fonte: Autores.

A maior produtividade da cultura de milho híbrido cultivar Piooner® 30F53 YH no município de Palotina/PR ocorreu no T6, superando em 126,33\% o T1 e 32,02\% o T2. Observa-se que os microrganismos A. brasilense proporcionaram incremento de produtividade independente da fonte e dose fornecida (Figura 3).

\section{Área experimental no município de São Miguel do Iguaçu/PR}

Os resultados da análise de variância referente ao estádio fenológico V10 das do milho híbrido Piooner® 30F53 YH, obtidos para a área do município de Toledo/PR. Verifica-se que às variáveis estudadas altura da planta (ALT) e massa seca total (MST) apresentaram efeitos significativos pelo teste $\mathrm{F},(\mathrm{p} \leq 0,01)$ (Tabela 9). Já a variável massa seca de folha (MSF) e o teor de nitrogênio foliar (TEN) apresentaram diferenças pelo teste $\mathrm{F},(\mathrm{p} \leq 0,05)$. Por outro lado, as variáveis diâmetro basal do colmo (DCB) e massa seca de colmo+bainha (MSCB), não diferiram estatisticamente nas condições testadas (Tabela 9). 
Tabela 9. Resumo da análise de variância e comparação de médias para altura da planta (ALT), diâmetro basal do colmo (DBC), massa de matéria seca de folhas (MSF), massa de matéria seca de colmo+bainha (MSCB), massa de matéria seca total (MST) e teor de nitrogênio foliar (TEN), de plantas de milho híbrido Piooner® 30F53 YH, município de São Miguel do Iguaçu/PR, 2017/2018.

\begin{tabular}{ccccccc}
\hline & ALT & DCB & MSCB & MSF & MST & TEN \\
\cline { 2 - 6 } TRA & $\mathrm{cm}$ & $\mathrm{mm}$ & $\mathrm{g}$ & $\mathrm{g}$ & $\mathrm{g}$ & \\
\hline T1 & $18,26 \mathrm{~b}$ & 4,01 & 5,93 & $7,79 \mathrm{~b}$ & $14,40 \mathrm{~b}$ & $1,29 \mathrm{~b}$ \\
T2 & $23,43 \mathrm{ab}$ & 5,35 & 6,58 & $8,47 \mathrm{~b}$ & $14,37 \mathrm{~b}$ & $1,48 \mathrm{~b}$ \\
T3 & $29,60 \mathrm{a}$ & 6,45 & 10,36 & $12,22 \mathrm{a}$ & $22,58 \mathrm{a}$ & $2,23 \mathrm{a}$ \\
T4 & $27,69 \mathrm{a}$ & 4,25 & 9,01 & $10,56 \mathrm{ab}$ & $19,57 \mathrm{ab}$ & $2,19 \mathrm{a}$ \\
T5 & $24,73 \mathrm{ab}$ & 5,18 & 8,07 & $9,76 \mathrm{ab}$ & $17,83 \mathrm{ab}$ & $1,51 \mathrm{~b}$ \\
T6 & $28,58 \mathrm{a}$ & 6,15 & 10,06 & $11,13 \mathrm{ab}$ & $21,19 \mathrm{a}$ & $2,18 \mathrm{a}$ \\
T7 & $29,60 \mathrm{a}$ & 6,65 & 9,10 & $10,59 \mathrm{ab}$ & $19,69 \mathrm{ab}$ & $2,03 \mathrm{a}$ \\
\hline C.V. & 24,52 & 13,28 & 15,87 & 12,76 & 17,41 & 20,96 \\
D.M.S. & 8,35 & 3,23 & 4,43 & 3,74 & 6,12 & 0,36 \\
F. & $14,15^{* *}$ & $1,47^{\mathrm{ns}}$ & $1,28^{\mathrm{ns}}$ & $4,70^{*}$ & $16,17^{* *}$ & $2,43^{*}$ \\
\hline
\end{tabular}

Não significativo (ns), ou significativo a $10(*)$ e $5 \%(* *)$, respectivamente pelo teste F. Médias seguidas de mesma letra minúscula na coluna, não diferem estatisticamente entre si pelo teste de Tukey $(\mathrm{p} \leq 0,05)$. C.V. Coeficiente de variação; D.M.S. Desvio mínimo significativo; F Calculado. T1 - $0 \mathrm{~kg} \mathrm{ha}^{-1}$ de nitrogênio $(\mathrm{N})$, sem inoculação (testemunha); T2 - $80 \mathrm{~kg} \mathrm{ha}^{-1}$ de N, sem inoculação; T3 - $160 \mathrm{~kg}$ $\mathrm{ha}^{-1}$ de N, sem inoculação; T4 - $80 \mathrm{~kg} \mathrm{ha}^{-1}$ de N + Inoculação com inoculante líquido registrado, contendo A. brasilense (Ab-V5 e Ab-V6), na dose de $100 \mathrm{~mL} 25 \mathrm{~kg}^{-1}$ de sementes; $\mathbf{T 5}-80 \mathrm{~kg} \mathrm{ha}^{-1} \mathrm{de} \mathrm{N}+$ inoculação de sementes com inoculante FERTIBIO Azospirillum 'Líquido' na dose de $100 \mathrm{~mL} 25 \mathrm{~kg}^{-1}$ de sementes; T6 - $80 \mathrm{~kg} \mathrm{ha}^{-1}$ de $\mathrm{N}+$ inoculação de sementes com inoculante FERTIBIO Azospirillum 'Líquido' na dose de $150 \mathrm{~mL} 25 \mathrm{~kg}^{-1}$ de sementes. T7 - $80 \mathrm{~kg} \mathrm{ha}^{-1}$ de N + inoculação de sementes com inoculante FERTIBIO Azospirillum 'Líquido'

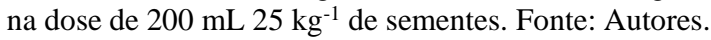

A altura média da planta de milho híbrido Piooner® 30F53 YH, determinado no município de São Miguel do Iguaçu/PR foi superior no tratamento T3 e T7, superando em 61,93\% o T1, seguido pelos tratamentos T4 e T6, que superaram em $51,48 \%$ e $56,35 \%$ o T1, respectivamente (Tabela 9).

Os valores médios da massa de matéria seca de folhas de milho (MSF) foi superior no T3, superando em $56,87 \%$ e $44,27 \%$ os tratamentos $\mathrm{T} 1$ e $\mathrm{T} 2$, respectivamente (Tabela 9). Todos os tratamentos que receberam metade da dose recomendada para a cultura associada com a inoculação de microrganismos promotores de crescimento não diferenciaram do tratamento com a dose completa de nitrogênio (T3). A média dos valores da variável matéria seca total de plantas (MST) foi superior no T3, superando em 56,87\% e 44,2\% os tratamentos T1 e T2, respectivamente (Tabela 9). Da mesma forma, o tratamento T6 também se destacou, superando em 47,15\% e 47,46\% T1 e T2, respectivamente.

O teor de nitrogênio nas folhas de milho (TEN) foi superior no T3, superando em 72,87\%, 50,68\%, 47,68\% os tratamentos T1, T2 e T5, seguido pelo tratamento T4, superior em 69,77\% o T1, 47,97\% o T2 e 45,03\% T5. Da mesma forma, nota-se destaque para o tratamento T6, superior em 68,99\% o T1, 47,30\% o T2 e 44,37\% T5. O tratamento T7 foi superior em $57,36 \%$ o T1, 37, $16 \%$ o T2 e $34,43 \%$ T5 (Tabela 9 ).

Todos as variáveis que fazem parte dos componentes da produção do milho híbrido Piooner® $30 \mathrm{F53}$ YH apresentaram diferenças significativas pelo teste $\mathrm{F},(\mathrm{p} \leq 0,01)$, com exceção da variável, diâmetro de espiga (DE, em mm), a qual não apresentou diferenças significativas (Tabela 10).

O comprimento médio de espiga do milho híbrido cultivar Piooner® 30F53 YH (CE), cultivados na área experimental de São Miguel do Iguaçu/PR foi maior no tratamento T3 superando em 26,44\% o T1 e 17,90\% o T2, seguidos pelo tratamento T6 que foi superior em 25,31\% o T1 e 16,84\% o T2, respectivamente (Tabela 10).

O número de fileiras de grãos por espiga (NFGE) foi menor no tratamento T1 comparado aos demais tratamentos testados. Quanto ao número médio de grãos por fileira na espiga (NGF), este foi inferior no T1, comparado a todos os demais 
Research, Society and Development, v. 10, n. 3, e8210311292, 2021

(CC BY 4.0) | ISSN 2525-3409 | DOI: http://dx.doi.org/10.33448/rsd-v10i3.11292

tratamentos com exceção de T2. A maior diferença foi observada foi de 38,61\% entre os tratamentos T3 e T1 (Tabela 10). O número médio total de grãos por espiga (NG) na área experimental de São Miguel do Iguaçu, foi superior no T3, superando em $67,16 \%$ o T1 e $22,93 \%$ o T2, respectivamente (Tabela 10 ).

Os valores médios da massa de mil grãos (MMG, em gramas), das plantas de milho híbrido Piooner® 30F53 YH cultivados na área experimental do município de São Miguel do Iguaçu/PR, safra 2017/2018 foram superiores no tratamento T3, superando em $35,11 \%$ o T2 (Figura 4).

Tabela 10. Resumo da análise de variância e comparação de médias para comprimento de espiga (CE), diâmetro de espiga (DE), número de fileiras de grãos por espiga (NFGE), número de grãos por fileira na espiga (NGF), número total de grãos por espiga (NG) e massa de mil grãos (MMG), de plantas de milho híbrido Piooner® 30F53 YH município de São Miguel do Iguaçu/PR, 2017/2018.

\begin{tabular}{ccccccc}
\hline & CE & DE & NFGE & NGF & NG & MMG \\
\cline { 2 - 6 } TRA & $\mathrm{cm}$ & $\mathrm{mm}$ & & & & $\mathrm{g}$ \\
\hline T1 & $17,66 \mathrm{c}$ & 6,41 & $14,34 \mathrm{~b}$ & $26,29 \mathrm{~b}$ & $362,00 \mathrm{c}$ & $124,36 \mathrm{~b}$ \\
T2 & $18,94 \mathrm{bc}$ & 7,10 & $16,04 \mathrm{a}$ & $31,75 \mathrm{ab}$ & $492,25 \mathrm{~b}$ & $131,95 \mathrm{ab}$ \\
T3 & $22,33 \mathrm{a}$ & 7,54 & $17,07 \mathrm{a}$ & $36,44 \mathrm{a}$ & $605,13 \mathrm{a}$ & $168,02 \mathrm{a}$ \\
T4 & $20,46 \mathrm{abc}$ & 7,37 & $16,69 \mathrm{a}$ & $35,28 \mathrm{a}$ & $577,00 \mathrm{ab}$ & $152,15 \mathrm{ab}$ \\
T5 & $20,75 \mathrm{abc}$ & 7,29 & $17,23 \mathrm{a}$ & $33,89 \mathrm{a}$ & $553,50 \mathrm{ab}$ & $139,56 \mathrm{ab}$ \\
T6 & $22,13 \mathrm{a}$ & 7,60 & $17,03 \mathrm{a}$ & $35,46 \mathrm{a}$ & $577,50 \mathrm{ab}$ & $159,12 \mathrm{ab}$ \\
T7 & $20,84 \mathrm{ab}$ & 7,43 & $16,67 \mathrm{a}$ & $35,42 \mathrm{a}$ & $569,25 \mathrm{ab}$ & $155,48 \mathrm{ab}$ \\
\hline C.V. & 16,50 & 13,05 & 13,94 & 17,13 & 18,59 & 14,35 \\
D.M.S. & 3,11 & 1,25 & 1,51 & 5,58 & 107,16 & 36,88 \\
F. & $6,29^{* *}$ & $1,41^{\mathrm{ns}}$ & $9,68^{* *}$ & $8,71^{* * *}$ & $13,24^{* *}$ & $11,45^{* *}$ \\
\hline
\end{tabular}

Não significativo (ns), ou significativo a $10(*)$ e $5 \%(* *)$, respectivamente pelo teste F. Médias seguidas de mesma letra minúscula na coluna, não diferem estatisticamente entre si pelo teste de Tukey $(\mathrm{p} \leq 0,05)$. C.V. Coeficiente de variação; D.M.S. Desvio mínimo significativo; F Calculado. T1 - $0 \mathrm{~kg} \mathrm{ha}^{-1}$ de nitrogênio (N), sem inoculação (testemunha); T2 - $80 \mathrm{~kg} \mathrm{ha}^{-1} \mathrm{de} \mathrm{N}$, sem inoculação; T3 - $160 \mathrm{~kg}$ $\mathrm{ha}^{-1}$ de N, sem inoculação; T4 - $80 \mathrm{~kg} \mathrm{ha}^{-1}$ de $\mathrm{N}$ + Inoculação com inoculante líquido registrado, contendo A. brasilense (Ab-V5 e Ab-V6), na dose de $100 \mathrm{~mL} 25 \mathrm{~kg}^{-1}$ de sementes; $\mathbf{T 5}-80 \mathrm{~kg} \mathrm{ha}^{-1}$ de $\mathrm{N}+$ inoculação de sementes com inoculante FERTIBIO Azospirillum 'Líquido' na dose de $100 \mathrm{~mL} 25 \mathrm{~kg}^{-1}$ de sementes; T6 - $80 \mathrm{~kg} \mathrm{ha}^{-1}$ de $\mathrm{N}+$ inoculação de sementes com inoculante FERTIBIO Azospirillum 'Líquido' na dose de $150 \mathrm{~mL} 25 \mathrm{~kg}^{-1}$ de sementes. T7 - $80 \mathrm{~kg} \mathrm{ha}^{-1}$ de $\mathrm{N}+$ inoculação de sementes com inoculante FERTIBIO Azospirillum 'Líquido'

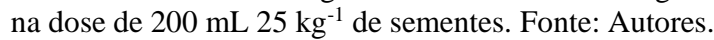

A maior produtividade da cultura de milho híbrido cultivar Piooner® 30F53 YH no município de São Miguel do Iguaçu/PR ocorreu no T6, superando em 126,33\% o T1 e 32,02\% o T2. A maior produtividade obtida da cultura de milho na área experimental do município de São Miguel do Iguaçu/PR foi o tratamento T3 $\left(66597,90 \mathrm{~kg} \mathrm{ha}^{-1}\right)$ superando em 66,35\% o T1 $\left(39665,22 \mathrm{~kg} \mathrm{ha}^{-1}\right)$ e 38,06\% o T2 $\left(4779,17 \mathrm{~kg} \mathrm{ha}^{-1}\right)$, seguidos do T5 (5984,65 $\left.\mathrm{kg} \mathrm{ha}^{-1}\right)$ superando em 48,88\% o T1 e $23,55 \%$ o T2. Da mesma forma, tratamento T6 (6191,10 kg ha-1) superou em 56,10\% o T1 e 29,54\% o T2, além do T7 $\left(66597,90 \mathrm{~kg} \mathrm{ha}^{-1}\right)$, que foi superior em $53,85 \%$ o T1 e $27,68 \%$ o T2, respectivamente. 
Figura 4. Produtividade de plantas de milho híbrido cultivar Piooner® 30F53 YH cultivadas sobre diferentes formas de inoculação de sementes com bactérias diazotróficas, no município de São Miguel do Iguaçu/PR Médias seguidas das mesmas letras minúsculas na coluna não diferem entre si pelo teste de Tukey a 5\%. CV = 17,18\%; DMS = 1119,86; e F cal = 38,51. T1 - $0 \mathrm{~kg} \mathrm{ha}^{-1}$ de nitrogênio (N), sem inoculação (testemunha); T2 - $80 \mathrm{~kg} \mathrm{ha}^{-1}$ de N, sem inoculação; T3 - $160 \mathrm{~kg} \mathrm{ha-1} \mathrm{de} \mathrm{N,} \mathrm{sem}$ inoculação; T4 - 80 kg ha-1 de N + Inoculação com inoculante líquido registrado, contendo A. brasilense (Ab-V5 e Ab-V6), na dose de $100 \mathrm{~mL} 25 \mathrm{~kg}^{-1}$ de sementes; T5 - $80 \mathrm{~kg} \mathrm{ha}^{-1}$ de $\mathrm{N}+$ inoculação de sementes com inoculante FERTIBIO Azospirillum 'Líquido' na dose de $100 \mathrm{~mL} 25 \mathrm{~kg}^{-1}$ de sementes; T6 - $80 \mathrm{~kg} \mathrm{ha}^{-1}$ de $\mathrm{N}+$ inoculação de sementes com inoculante FERTIBIO Azospirillum 'Líquido' na dose de $150 \mathrm{~mL} 25 \mathrm{~kg}^{-1}$ de sementes. T7 - $80 \mathrm{~kg} \mathrm{ha}^{-1}$ de $\mathrm{N}+$ inoculação de sementes com inoculante FERTIBIO Azospirillum 'Líquido' na dose de $200 \mathrm{~mL} 25 \mathrm{~kg}^{-1}$ de sementes.

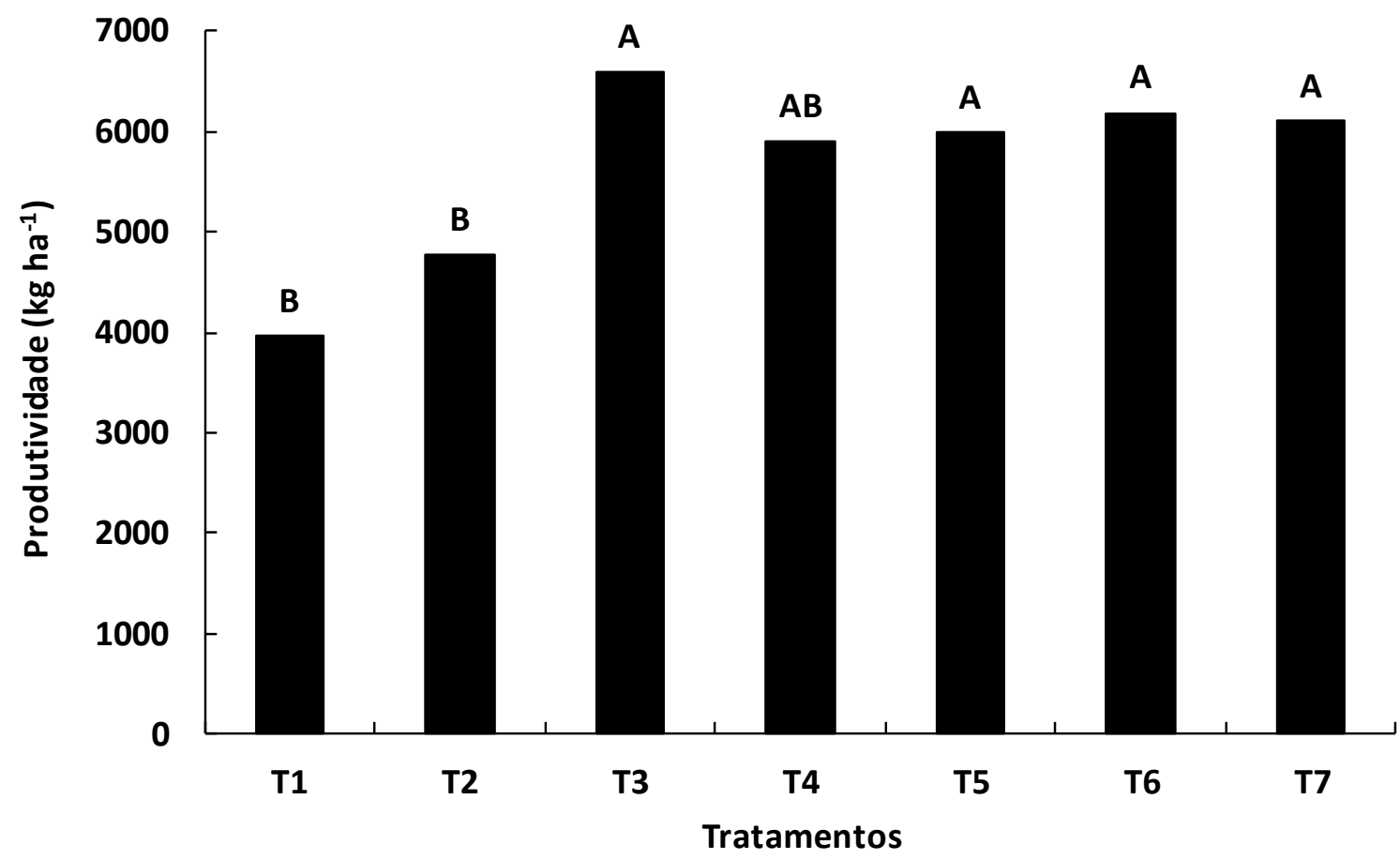

Fonte: Autores.

Todos os tratamentos que receberam $50 \%$ da recomendação agronômica de fornecimento de nitrogênio associado a qualquer formulação de microrganismo promotores de crescimento, apresentando resultados não diferentes estatisticamente que o tratamento que recebeu $100 \%$ da recomendação.

\section{Área experimental no município de Cascavel/PR}

Ao avaliar os resultados da análise de variância do experimento conduzido na área experimental de Cascavel/PR, verificou-se que todas as variáveis estudadas no estádio V10 apresentaram efeitos significativos pelo teste $F$ ( $p \leq 0,01$ ), com exceção da variável altura da planta (ALT) (Tabela 11). 
Tabela 11. Resumo da análise de variância e comparação de médias para altura da planta (ALT), diâmetro basal do colmo (DBC), massa de matéria seca de folhas (MSF), massa de matéria seca de colmo+bainha (MSCB), massa de matéria seca total (MST) e teor de nitrogênio (TEN), de plantas de milho híbrido Piooner@ 30F53 YH, município de Cascavel/PR, $2017 / 2018$.

\begin{tabular}{ccccccc}
\hline & ALT & DCB & MSCB & MSF & MST & TEN \\
\cline { 2 - 7 } TRA & $\mathrm{cm}$ & $\mathrm{mm}$ & $\mathrm{g}$ & $\mathrm{g}$ & $\mathrm{g}$ & \\
\hline T1 & 29,43 & $4,70 \mathrm{~b}$ & $9,33 \mathrm{bc}$ & $10,68 \mathrm{c}$ & $20,01 \mathrm{c}$ & $1,25 \mathrm{~b}$ \\
T2 & 33,99 & $7,04 \mathrm{ab}$ & $10,21 \mathrm{bc}$ & $13,22 \mathrm{bc}$ & $23,43 \mathrm{bc}$ & $2,03 \mathrm{ab}$ \\
T3 & 40,52 & $10,74 \mathrm{a}$ & $14,26 \mathrm{a}$ & $18,59 \mathrm{a}$ & $32,85 \mathrm{a}$ & $2,92 \mathrm{a}$ \\
T4 & 36,51 & $8,25 \mathrm{ab}$ & $12,99 \mathrm{ab}$ & $15,76 \mathrm{abc}$ & $28,75 \mathrm{abc}$ & $2,34 \mathrm{ab}$ \\
T5 & 33,79 & $7,39 \mathrm{ab}$ & $11,33 \mathrm{abc}$ & $15,48 \mathrm{abc}$ & $26,81 \mathrm{abc}$ & $2,27 \mathrm{ab}$ \\
T6 & 32,81 & $9,38 \mathrm{ab}$ & $12,95 \mathrm{abc}$ & $17,30 \mathrm{ab}$ & $30,25 \mathrm{ab}$ & $2,61 \mathrm{a}$ \\
T7 & 38,93 & $9,58 \mathrm{ab}$ & $11,29 \mathrm{abc}$ & $17,02 \mathrm{ab}$ & $28,31 \mathrm{abc}$ & $3,01 \mathrm{a}$ \\
\hline C.V. & 13,38 & 9,24 & 17,48 & 11,88 & 14,28 & 13,91 \\
D.M.S. & 7,16 & 5,56 & 3,67 & 5,32 & 9,08 & 1,13 \\
F. & $2,59^{\mathrm{ns}}$ & $8,44^{* *}$ & $8,23^{* *}$ & $5,69^{* *}$ & $14,40^{* *}$ & $4,91^{* *}$ \\
\hline
\end{tabular}

Não significativo (ns), ou significativo a $10(*)$ e $5 \%(* *)$, respectivamente pelo teste F. Médias seguidas de mesma letra minúscula na coluna, não diferem estatisticamente entre si pelo teste de Tukey $(\mathrm{p} \leq 0,05)$. C.V. Coeficiente de variação; D.M.S. Desvio mínimo significativo; F Calculado. T1 - $0 \mathrm{~kg} \mathrm{ha}^{-1}$ de nitrogênio (N), sem inoculação (testemunha); T2 - $80 \mathrm{~kg} \mathrm{ha}^{-1}$ de N, sem inoculação; T3 - $160 \mathrm{~kg}$ ha $^{-1}$ de N, sem inoculação; $\mathbf{T} 4-80 \mathrm{~kg} \mathrm{ha}^{-1}$ de $\mathrm{N}+$ Inoculação com inoculante líquido registrado, contendo A. brasilense (Ab-V5 e Ab-V6), na dose de $100 \mathrm{~mL} 25 \mathrm{~kg}^{-1}$ de sementes; $\mathbf{T 5}-80 \mathrm{~kg} \mathrm{ha}^{-1}$ de $\mathrm{N}+$ inoculação de sementes com inoculante FERTIBIO Azospirillum 'Líquido' na dose de $100 \mathrm{~mL} 25 \mathrm{~kg}^{-1}$ de sementes; T6 - $80 \mathrm{~kg} \mathrm{ha}^{-1}$ de $\mathrm{N}+$ inoculação de sementes com inoculante FERTIBIO Azospirillum 'Líquido' na dose de $150 \mathrm{~mL} 25 \mathrm{~kg}^{-1}$ de sementes. T7 - $80 \mathrm{~kg} \mathrm{ha}^{-1}$ de $\mathrm{N}+$ inoculação de sementes com inoculante FERTIBIO Azospirillum 'Líquido' na dose de $200 \mathrm{~mL} 25 \mathrm{~kg}^{-1}$ de sementes. Fonte: Autores.

Os valores médios diâmetro basal do colmo de milho (DBC) foi superior no T3 em 128,40\% comparado ao T1. A massa de matéria seca de folhas de milho (MSF) foi superior no T3, superando em 52,84\% e 39,67\% os tratamentos T1 e T2, respectivamente (Tabela 11). Todos os tratamentos que receberam metade da dose recomendada para a cultura associada com a inoculação de microrganismos promotores de crescimento não diferenciaram do tratamento com a dose completa de nitrogênio (T3).

A massa de matéria seca de folhas de milho (MSF) foi superior no T3, superando em 74,06\% e 40,62\% os tratamentos T1 e T2, respectivamente. A menor média dos valores da variável matéria seca total de plantas (MST) foram observadas no T1, sendo inferior em 39,09\% comparada a T3, seguidos do tratamento T2 sendo inferior em 14,60\% de T3 (Tabela 11). Quanto ao teor de nitrogênio nas folhas de milho (TEN), estes foram superiores nos tratamentos T7, T3 e T6, superando em $140,80 \%, 133,60 \%$ e $108,80 \%$ o T1, respectivamente (Tabela 11 ).

Todas as variáveis que fazem parte dos componentes da produção do milho híbrido Piooner® $30 \mathrm{~F} 53$ YH obtidos da

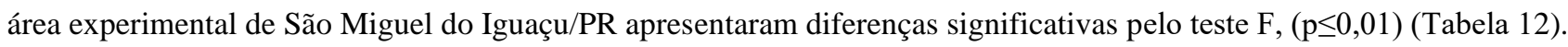


Tabela 12. Resumo da análise de variância e médias para comprimento de espiga (CE), diâmetro de espiga (DE), número de fileiras de grãos por espiga (NFGE), número de grãos por fileira na espiga (NGF), número total de grãos por espiga (NG) e massa de mil grãos (MMG), de plantas de milho híbrido Piooner® 30F53 YH, município de Cascavel/PR, 2017/2018.

\begin{tabular}{ccccccc}
\hline & CE & DE & NFGE & NGF & NG & MMG \\
\cline { 2 - 7 } TRA & Cm & mm & & & & $\mathrm{g}$ \\
\hline T1 & $9,69 \mathrm{c}$ & $5,43 \mathrm{~b}$ & $12,67 \mathrm{~b}$ & $20,16 \mathrm{c}$ & $255,43 \mathrm{c}$ & $131,71 \mathrm{~b}$ \\
T2 & $12,10 \mathrm{~b}$ & $5,94 \mathrm{~b}$ & $14,70 \mathrm{a}$ & $23,75 \mathrm{bc}$ & $349,13 \mathrm{~b}$ & $134,62 \mathrm{~b}$ \\
T3 & $15,52 \mathrm{a}$ & $6,27 \mathrm{a}$ & $14,25 \mathrm{a}$ & $28,90 \mathrm{a}$ & $411,83 \mathrm{ab}$ & $174,80 \mathrm{a}$ \\
T4 & $14,84 \mathrm{a}$ & $6,09 \mathrm{ab}$ & $14,31 \mathrm{a}$ & $27,83 \mathrm{ab}$ & $398,25 \mathrm{ab}$ & $156,32 \mathrm{ab}$ \\
T5 & $14,39 \mathrm{a}$ & $6,11 \mathrm{ab}$ & $14,58 \mathrm{a}$ & $27,90 \mathrm{a}$ & $406,78 \mathrm{ab}$ & $142,84 \mathrm{~b}$ \\
T6 & $14,94 \mathrm{a}$ & $6,35 \mathrm{a}$ & $14,73 \mathrm{a}$ & $29,26 \mathrm{a}$ & $431,00 \mathrm{a}$ & $173,94 \mathrm{a}$ \\
T7 & $14,38 \mathrm{a}$ & $6,01 \mathrm{ab}$ & $14,42 \mathrm{a}$ & $26,85 \mathrm{ab}$ & $387,18 \mathrm{ab}$ & $152,49 \mathrm{ab}$ \\
\hline C.V. & 15,70 & 13,59 & 14,01 & 16,65 & 17,51 & 15,29 \\
D.M.S. & 1,82 & 0,73 & 1,33 & 4,10 & 66,17 & 31,42 \\
F. & $28,15^{* *}$ & $14,20^{* *}$ & $6,34^{* *}$ & $14,06^{* *}$ & $177,49^{* *}$ & $7,93^{* *}$ \\
\hline
\end{tabular}

Não significativo (ns), ou significativo a $10(*)$ e $5 \%(* *)$, respectivamente pelo teste F. Médias seguidas de mesma letra minúscula na coluna, não diferem estatisticamente entre si pelo teste de Tukey $(\mathrm{p} \leq 0,05)$. C.V. Coeficiente de variação; D.M.S. Desvio mínimo significativo; F Calculado. T1 - $0 \mathrm{~kg} \mathrm{ha}^{-1}$ de nitrogênio $(\mathrm{N})$, sem inoculação (testemunha); T2 - $80 \mathrm{~kg} \mathrm{ha}^{-1}$ de N, sem inoculação; T3 - $160 \mathrm{~kg}$ $\mathrm{ha}^{-1}$ de N, sem inoculação; T4 - $80 \mathrm{~kg} \mathrm{ha}^{-1}$ de $\mathrm{N}$ + Inoculação com inoculante líquido registrado, contendo A. brasilense (Ab-V5 e Ab-V6), na dose de $100 \mathrm{~mL} 25 \mathrm{~kg}^{-1}$ de sementes; $\mathbf{T 5}-80 \mathrm{~kg} \mathrm{ha}^{-1}$ de $\mathrm{N}+$ inoculação de sementes com inoculante FERTIBIO Azospirillum 'Líquido' na dose de $100 \mathrm{~mL} 25 \mathrm{~kg}^{-1}$ de sementes; T6 - $80 \mathrm{~kg} \mathrm{ha}^{-1}$ de $\mathrm{N}+$ inoculação de sementes com inoculante FERTIBIO Azospirillum 'Líquido' na dose de $150 \mathrm{~mL} 25 \mathrm{~kg}^{-1}$ de sementes. T7 - $80 \mathrm{~kg} \mathrm{ha}^{-1}$ de $\mathrm{N}+$ inoculação de sementes com inoculante FERTIBIO Azospirillum 'Líquido' na dose de $200 \mathrm{~mL} 25 \mathrm{~kg}^{-1}$ de sementes. Fonte: Autores.

O menor comprimento médio de espiga do milho híbrido cultivar Piooner® 30F53 YH (CE), cultivados na área experimental de Cascavel/PR foi o T1 comparado aos demais tratamentos (Tabela 12). No entanto, ao analisar o comportamento do tratamento que recebeu apenas $50 \%$ da recomendação de nitrogênio T2, nota-se que o fornecimento de inoculante independentemente da forma ou dose fornecida proporcionou valores superiores em 52,64\% $\mathrm{T} 4$, 31,57\% $\mathrm{T} 5$, $57,11 \%$ T6 e $31,07 \%$ T7 comparados ao tratamento T2 (Tabela 12).

O Diâmetro de espiga (DE) foi maior no tratamento T6 superando em 16,94\% o T1 e 6,90\% o T2, seguido do tratamento T3 em 15,4\% o T1 e 5,56\% o T2, respectivamente. Quanto ao número de fileiras de grãos por espiga (NFGE), este foi menor em T1 comparado a todos os demais tratamentos. (Tabela 12).

O número médio de grãos por fileira na espiga (NGF) foi maior no tratamento T6, superando em 45,14\% o T1 e 23,20 o T2, seguidos de T3 maior que 43,35\% o T1 e 21,68\% o T2, além de T5 superior em 38,39\% o T1 e 17,47\% o T2, respectivamente. Já, o número médio total de grãos por espiga (NG) na área experimental de Cascavel, foi superior no T6, superando em $68,74 \%$ o T1 e $23,45 \%$ o T2, respectivamente (Tabela 12).

Os valores médios da massa de mil grãos (MMG, em gramas), das plantas de milho híbrido Piooner® $30 \mathrm{F53}$ YH cultivados na área experimental do município de Cascavel/PR, safra 2017/2018 foram superiores no tratamento T3 e T6, superando em $32,72 \%$ e $32,06 \%$ o T1 e $29,85 \%$ e $29,21 \%$ o T2, respectivamente (Tabela 12).

A maior produtividade da cultura de milho híbrido cultivar Piooner® 30F53 YH no município de cascavel/PR ocorreu no T6, superando em 126,33\% o T1 e 32,02\% o T2 (Figura 5). A maior produtividade obtida da cultura de milho na área experimental do município de Cascavel/PR foi obtida nos tratamentos T3 (5723,67 kg ha-1), T4 (5116,27 kg ha-1), T5 (4808,66 $\left.\mathrm{kg} \mathrm{ha}{ }^{-1}\right)$, T6 $\left(5452,24 \mathrm{~kg} \mathrm{ha}^{-1}\right)$ e T7 (5368,92 $\left.\mathrm{kg} \mathrm{ha}^{-1}\right)$, comparados aos demais tratamentos. O fornecimento de qualquer formulação ou dose proporcionou resultados estatisticamente semelhantes ao tratamento T3. 
Figura 5. Produtividade de plantas de milho cultivadas sobre diferentes formas de inoculação de sementes com bactérias diazotróficas, no município de Cascavel/PR Médias seguidas das mesmas letras minúsculas na coluna não diferem entre si pelo teste de Tukey a 5\%. CV $=18,10 \%$; DMS $=994,23$; e F cal = 43,96. . T1 - 0 kg ha ${ }^{-1}$ de nitrogênio (N), sem inoculação (testemunha); T2 - $80 \mathrm{~kg} \mathrm{ha}^{-1}$ de N, sem inoculação; T3 - $160 \mathrm{~kg} \mathrm{ha}^{-1} \mathrm{de} \mathrm{N}$, sem inoculação; T4 - 80 kg ha ${ }^{-1}$ de N + Inoculação

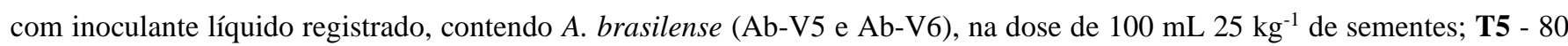
$\mathrm{kg} \mathrm{ha}^{-1}$ de $\mathrm{N}+$ inoculação de sementes com inoculante FERTIBIO Azospirillum 'Líquido' na dose de $100 \mathrm{~mL} 25 \mathrm{~kg}^{-1}$ de sementes; T6 - $80 \mathrm{~kg} \mathrm{ha}^{-1}$ de N + inoculação de sementes com inoculante FERTIBIO Azospirillum 'Líquido' na dose de 150 mL $25 \mathrm{~kg}^{-1}$ de sementes. T7 - $80 \mathrm{~kg} \mathrm{ha}^{-1}$ de $\mathrm{N}+$ inoculação de sementes com inoculante FERTIBIO Azospirillum 'Líquido' na dose de $200 \mathrm{~mL} 25 \mathrm{~kg}^{-1}$ de sementes.

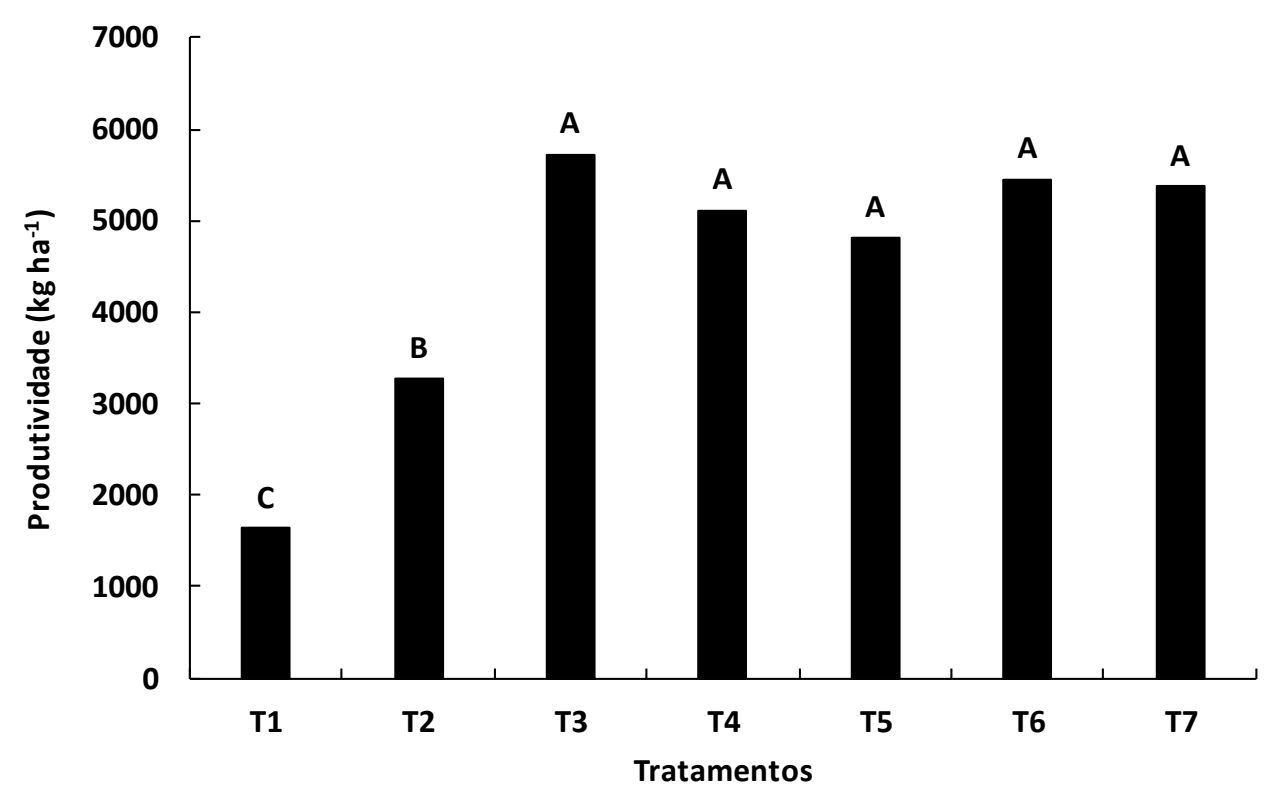

Fonte: Autores.

\section{Discussão}

O milho é um dos principais cereais produzido em mundo todo, porém este fato faz com que a cultura demande diretamente de altas quantidades de insumos, o que gera elevados impactos ambientais, visto que esses insumos provem ou dependem de fontes não renováveis para sua produção.

Atualmente o cenário mundial estima um aumento na escala populacional, o que demandará da agricultura maiores produtividade, sem elevar a área cultivada e com menores impactos ambientais. Desta forma, a principal opção estudada e consolidada em países como o Brasil, está a fixação biológica de nitrogênio (FBN). Esta técnica, possibilita por meio da inoculação de microrganismos o cultivo de diferentes plantas sem a utilização ou de forma parcial da adubação nitrogenada, gerando maior economia na cadeia produtiva e menores impactos ambientais. Todavia, diferentes empresas buscam diariamente diferentes mecanismos e métodos de elevar a produtividade da cultura do milho sempre de forma sustentável, nesse sentido tem sido crescente os trabalhos que abordam a inoculação em sementes de milho (Araújo, et al., 2014; Rockenbach, et al., 2017; Morais, et al., 2017). Esta técnica consiste em utilizar bactérias de efeito benéfico as plantas e que realizaram uma interação harmônica, onde estas diferentes espécies se beneficiam (BENINTENDE et al., 2010).

No caso da cultura do milho, os estudos envolvem a espécie Azospirillum brasilense, uma espécies de bactérias fixação biológica de nitrogênio e promotora de crescimento vegetal (Perrig et al., 2007), respectivamente. De modo geral, neste estudo, envolvendo os quatro diferentes locais, foi possível constatar por meio dos resultados positivos que os 
tratamentos que receberam microrganismos associados com redução de $50 \%$ do fornecimento recomendado de nitrogênio da cultura (T5, T6 e T7). Pode se dizer que provavelmente as plantas de milhos foram influenciada pelos hormônios vegetais tendo nos níveis de auxinas, citocininas e etileno efeito regulatório pronunciado na divisão e expansão celular (Fei \& Vessey, 2004), tendo a auxina e citocinina efeito direto sobre o desenvolvimento dos sistemas radiculares. Nesse sentido o $A$. brasilense atua em níveis hormonais elevando os teores de hormônios na planta, devido as mesma produzem e excretam os mesmo, principalmente o ácido-indol-acético (Radwan et al., 2005).

Sementes de trigo sofreram influência na germinação devido a interação de adubação nitrogenada e doses de $A$. brasilense favorecendo o comprimento das estruturas radiculares e parte aérea das plantas (Alves et al., 2017). Resultados semelhantes sobre a germinação de sementes e o desenvolvimento inicial de plântulas de trigo e milho foram observados quando inoculadas com A. brasilense e Herbaspirillum seropedicae (Dartora et al., 2013). Nesse sentido, outros estudos demonstram o efeito do Azospirillum em outras cultura como a do feijoeiro, onde concluíram que na redução do fornecimento de nitrogênio em cobertura a inoculação de sementes com Azospirillum brasilense proporcionou maior teor de $\mathrm{N}$ foliar, corroborando com o demostrado no presente estudo (Gitti et al., 2012).

Os resultados encontrados neste experimento com os diferentes locais de estudo corroboram com os observados na literatura para a cultura do milho onde a adubação nitrogenada e A. brasilense interagem proporcionando excelentes resultados. Os incrementos em massa seca de raiz nas plantas inoculadas relaciona-se ao maior desenvolvimento e alongamento celular nesse órgão vegetal. As bactérias da espécie A. brasilense estimulam o desenvolvimento radicular pelos hormônios que a mesma disponibiliza, além de incrementar a formação de pelos radiculares e raízes secundárias (Cassán et al., 2009; Rodrigues et al., 2014).

Quando se considera os componentes de produção e produtividade os incrementos providos nas plantas inoculadas podem ocorrem pelo melhor desenvolvimento vegetativo e acumulo de nitrogênio em parte aérea. Como o nitrogênio é majoritário para a planta, visto se alto teor de proteínas, quando maior a disponibilidade do nutriente na planta, maior a possibilidade de formação de estruturas reprodutivas como flores e vagens, bem como sua manutenção, acarretando em maior produtividade das culturas.

Desta forma, o uso da inoculação se mostrou agronomicamente eficiente na cultura do milho, com inoculantes da empresa FERTIBIO Azospirillum, líquido, na dose de $100 \mathrm{~mL}$, igualando ou superando o tratamento com uso do nitrogênio mineral e ao tratamento padrão de inoculação utilizado atualmente. Sendo assim torna-se possível a sua utilização como técnica que visa aumentar a produtividade da cultura da soja, aliado a uma agricultura sustentável e mais harmônica com a natureza.

\section{Considerações Finais}

Baseando-se nos resultados obtidos nas quatro áreas experimentais, com as condições edafoclimáticas apresentadas, pode-se concluir que:

$\mathrm{O}$ inoculante líquido contendo a bactéria promotora de crescimento vegetal Azospirillum brasiliense (estirpes Ab-V5 e Ab-V6), aplicado via inoculação de sementes, anteriormente à semeadura, na doses de $100 \mathrm{~mL} 25 \mathrm{~kg}^{-1}$ de sementes, com metade da dose de nitrogênio recomendado para a cultura, apresentou eficiência agronômica, resultando em produtividade estatisticamente superior à testemunha e semelhante ao tratamento que recebeu a dose de nitrogênio recomendada para a cultura e ao tratamento que recebeu inoculante padrão já registrado no MAPA e metade da dose de nitrogênio recomendado para a cultura. 
Research, Society and Development, v. 10, n. 3, e8210311292, 2021

(CC BY 4.0) | ISSN 2525-3409 | DOI: http://dx.doi.org/10.33448/rsd-v10i3.11292

\section{Referências}

Alves, S. R. de P., Francisco, A. L. O. de \& Carvalho, T. C. de (2017). Azospirillum brasilense e nitrogênio: atuação no potencial fisiológico de sementes de trigo. Brazilian Journal of Applied Technology for Agricultural Science, Guarapuava, PR, 10(2), 43-51. http://dx.doi.org/10.5935/PAeT.V10.N2.04

Araújo, R. M., Araújo, A. S. F. de, Nunes, L. A. P. L. \& Figueiredo, M. V. B. do (2014). Resposta do milho verde à inoculação com Azospirillum brasilense e níveis de nitrogênio. Ciência Rural, Santa Maria, 44(9), 1556-1560. http://dx.doi.org/10.1590/0103-8478cr20130355

Baldani, J. I. \& Baldani, V. L. D. (2005). History on the biological nitrogen fixation research in graminaceous plants: Special emphasis on the Brazilian experience. Anais da Academia Brasileira de Ciências, 77, 549-579. https://www.scielo.br/scielo.php?script=sci_arttext\&pid=S0001-37652005000300014

Benintende, S., Uhrich, W., Herrera, M., Gangge, F., Sterren, M. \& Benintende M. (2010) Comparación entre coinoculación com Bradyrhizobium japonicum y Azospirillum brasilense e inoculación simple con Bradyrhizobium japonicum en la nodulación, crecimiento y acumulación de N en el cultivo de soja. Agriscientia, 23(2), 71-77. https://revistas.unc.edu.ar/index.php/agris/article/view/2768.

Cassán, F., Perrig, D., Sgroy, V., Masciarelli, O., Penna, C. \& Luna, V. (2009). Azospirillum brasilense Az39 and Brandyrhizobium japonicum E109, inoculated singly or in combination, promote seed germination and early seedling growth in corn (Zea mays L.) and sobybean (Glycine max L.). European Journal of Soil Biology. 45, 28-35. http://doi:10.1016/j.ejsobi.2008.08.005

Cruz, C. D. (2006). Programa GENES: biometria. Viçosa: UFV, 382. http://arquivo.ufv.br/dbg/genes/genes_Br.htm

Dartora, J., Guimarães, V. F., Marini, D. \& Sander, G. (2013). Adubação nitrogenada associada à inoculação com Azospirillum brasilense e Herbaspirillum seropedicae na cultura do milho. Revista Brasileira de Engenharia Agrícola e Ambiental, 17(10), 1023-1029. http://dx.doi.org/10.1590/S141543662013001000001

Döbereiner, J. \& Ruschel, A. P. (1958). Uma nova espécie de Beijerinckia. Revista de Biologia, Lisboa, 1, $261-272$.

Döbereiner, J. (1966). Azotobacter paspali sp.n., uma bactéria fixadora de nitrogênio na rizosfera de Paspalum. Pesquisa Agropecuária Brasileira. 1, 357-365.

Döbereiner, J. (1997). Biological nitrogen fixation in the tropics: social and economic contributions. Soil Biol Biochem, $29,174-771$. https://doi.org/10.1016/S0038-0717(96)00226-X

Embrapa - Empresa Brasileira de Pesquisa Agropecuária (2013). Sistema brasileiro de classificação de solos. (3a ed.), Brasília, Embrapa, 353p.

Embrapa - Empresa Brasileira de Pesquisa Agropecuária. (2009). Manual de Análises Químicas de Solos, Plantas e Fertilizantes. (2a ed.), Brasília, Informação Tecnológica, 628p.

Embrapa - Empresa Brasileira de Pesquisa Agropecuária (2012). Sistema de Produção - Milho, 1. (8a ed.) Embrapa Milho e Sorgo.

Embrapa - Empresa Brasileira de Pesquisa Agropecuária (2011). Centro Nacional de Pesquisas de Solos. Manual de métodos de análises de solos. (2a ed.), Rio de Janeiro: Embrapa Solos, 230p.

Fei, H. \& Vessey, J. K. (2004). Further investigation of the roles of auxin and cytokinin in the NH4 1-induced stimulation of nodulation using white clover transformed with the auxin-sensitive reporter GH3: gusA. Physiologia Plantarum, 12, 674-681. https://doi.org/10.1111/j.1399-3054.2004.00358.x

Gitti, D. de C., Arf, O., Kaneko, F. H., Rodrigues, R. A. F., Buzetiér, S., Portugal, J. R. \& Corsini, D. C. D. C. (2012). Inoculação de Azospirillum brasilense em cultivares de feijões cultivados no inverno. Revsita Agrarian, 5 (15), 36-46. https://doi.org/10.30612/agrarian.v5il5.1297.

Köppen, W. \& Geiger, R. (1928). Klimate der Erde. Gotha: Verlag Justus Perthes.

Kuss, A.V., Kuss, V. V., Lovato, T. \& Flôres, M. L. (2007) Fixação de nitrogênio e produção de ácido indolacético in vitro por bactérias diazotróficas endofíticas. Pesquisa Agropecuária Brasileira, 42, 1459-1465. https://doi.org/10.1590/S0100-204X2007001000013.

Morais, G. P., Gomes, V. F. F., Mendes Filho, P. F., Almeida, A. M. M. de \& Silva Júnior, J. M. T. (2017). Adubação nitrogenada associada à inoculação com Azospirillum brasilense na cultura do milho. Revista Agropecuária Técnica. Areia, PB, 38(3), 109-116. file:///C:/Users/Usuario/Downloads/29919Texto\%20do\%20Artigo-85735-1-10-0171017.pdf

Perrig D., Boiero M. L., Masciarelli O. A., Penna C., Ruiz O. A., Cassán F. D. et al. (2007). Plant-growth-promoting compounds produced by two agronomically important strains of Azospirillum brasilense, and implications for inoculant formulation. Appl. Microbiol. Biotechnol. 75, 11431150. https://doi.org/doi: 10.1007 / s00253-007-0909-9.

Radwan, T. El-S. El-D, Mohamed, Z. K. \& Reis, V. M. (2005). Aeração e adição de sais na produção de ácido indol acético por bactérias diazotróficas. Pesquisa Agropecuária Brasileira, Brasília, 40(10), 997-1004. https://doi.org/10.1590/S0100-204X2005001000008.

Rockenbach, M. D. A., Alvarez, J. W. R., Fois, D. A. F., Tiecher, T., Karajallo, J. C. \& Trinidad, S. A. (2017). Eficiência da aplicação de Azospirillum brasilense associado ao nitrogênio na cultura do milho. Acta Iguazu, Cascavel, 6(1), 33-44. https://doi.org/10.48075/actaiguaz.v6i1.16558.

Rodrigues, L. F. O. S., Guimarães, V. F., Silva, M. B., Pinto Junior, A. S. \& Klein, J., Costa, A. C. P. R. (2014). Caracterí sticas agronômicas do trigo em função de Azospirillum brasilense, ácidos húmicos e nitrogênio em casa de vegetação. Revista Brasileira de Engenharia Agrícola e Ambiental. 18, 7-31. https://doi.org/10.1590/S1415-43662014000100005. 